\title{
The Search for Natural and Synthetic Inhibitors That Would Complement Antivenoms as Therapeutics for Snakebite Envenoming
}

\author{
José María Gutiérrez ${ }^{1, *} \mathbb{0}$, Laura-Oana Albulescu ${ }^{2}$, Rachel H. Clare ${ }^{2}$, Nicholas R. Casewell ${ }^{2} \mathbb{}$, \\ Tarek Mohamed Abd El-Aziz ${ }^{3,4}{ }^{-}$, Teresa Escalante $^{1}$ and Alexandra Rucavado ${ }^{1}$ \\ 1 Facultad de Microbiología, Instituto Clodomiro Picado, Universidad de Costa Rica, \\ San José 11501, Costa Rica; teresa.escalante@ucr.ac.cr (T.E.); alexandra.rucavado@ucr.ac.cr (A.R.) \\ 2 Centre for Snakebite Research \& Interventions, Liverpool School of Tropical Medicine, Liverpool L3 5QA, UK; \\ Laura-Oana.Albulescu@lstmed.ac.uk (L.-O.A.); rachel.clare@lstmed.ac.uk (R.H.C.); \\ Nicholas.casewell@lstmed.ac.uk (N.R.C.) \\ 3 Zoology Department, Faculty of Science, Minia University, El-Minia 61519, Egypt; mohamedt1@uthscsa.edu \\ 4 Department of Cellular and Integrative Physiology, University of Texas Health Science Center at San Antonio, \\ San Antonio, TX 78229-3900, USA \\ * Correspondence: jose.gutierrez@ucr.ac.cr
}

Citation: Gutiérrez, J.M.; Albulescu, L.-O.; Clare, R.H.; Casewell, N.R.;

Abd El-Aziz, T.M.; Escalante, T.;

Rucavado, A. The Search for Natural and Synthetic Inhibitors That Would Complement Antivenoms as

Therapeutics for Snakebite

Envenoming. Toxins 2021, 13, 451.

https://doi.org/10.3390/

toxins13070451

Received: 30 May 2021

Accepted: 27 June 2021

Published: 29 June 2021

Publisher's Note: MDPI stays neutral with regard to jurisdictional claims in published maps and institutional affiliations.

Copyright: (c) 2021 by the authors. Licensee MDPI, Basel, Switzerland. This article is an open access article distributed under the terms and conditions of the Creative Commons Attribution (CC BY) license (https:/ / creativecommons.org/licenses/by/ $4.0 /)$.

\begin{abstract}
A global strategy, under the coordination of the World Health Organization, is being unfolded to reduce the impact of snakebite envenoming. One of the pillars of this strategy is to ensure safe and effective treatments. The mainstay in the therapy of snakebite envenoming is the administration of animal-derived antivenoms. In addition, new therapeutic options are being explored, including recombinant antibodies and natural and synthetic toxin inhibitors. In this review, snake venom toxins are classified in terms of their abundance and toxicity, and priority actions are being proposed in the search for snake venom metalloproteinase (SVMP), phospholipase $\mathrm{A}_{2}\left(\mathrm{PLA}_{2}\right)$, three-finger toxin (3FTx), and serine proteinase (SVSP) inhibitors. Natural inhibitors include compounds isolated from plants, animal sera, and mast cells, whereas synthetic inhibitors comprise a wide range of molecules of a variable chemical nature. Some of the most promising inhibitors, especially SVMP and PLA 2 inhibitors, have been developed for other diseases and are being repurposed for snakebite envenoming. In addition, the search for drugs aimed at controlling endogenous processes generated in the course of envenoming is being pursued. The present review summarizes some of the most promising developments in this field and discusses issues that need to be considered for the effective translation of this knowledge to improve therapies for tackling snakebite envenoming.
\end{abstract}

Keywords: snake venom; antivenom; inhibitors; metalloproteinases; phospholipases $\mathrm{A}_{2}$; three finger toxins; peptidomimetic hydroxamates; varespladib

Key Contribution: The search for natural and synthetic inhibitors of snake venom key toxins is reviewed. The main types of inhibitors are described, and their mechanism of action summarized. Key aspects in the design of preclinical tests for assessing the efficacy of these inhibitors are discussed.

\section{The Treatment of Snakebite Envenoming: A Challenging Task in Need of Innovation}

Snakebite envenomings represent an impactful global public health problem, with the highest incidences occurring in Sub-Saharan Africa, Asia, and Latin America [1,2]. It is estimated that between 1.8 and 2.7 million cases of snakebite envenoming occur annually, resulting in 81,000 to 138,000 fatalities and more than 400,000 people left with permanent sequelae [2]. Snakebite envenoming is a neglected tropical disease [3] since it largely affects impoverished communities with little political voice and contributes to the perpetuation of a vicious cycle of poverty [4,5], hence fulfilling the basic features of these diseases $[6,7]$. 
This has prompted international efforts to raise awareness on the impact of this disease and on the need to implement effective strategies to confront it [8-11]. Consequently, in 2018, the World Health Assembly approved a resolution that urged member states to take action for the prevention and control of snakebites [12], and a global strategy aimed at reducing the number of deaths and disabilities caused by envenomings by $50 \%$ by the year 2030 was launched by the World Health Organization (WHO) in 2019 [13].

One of the four pillars of this global strategy is to 'ensure safe, effective treatment' [11]. Since the last decade of the 19th century, the mainstay treatment for snakebite envenoming is the timely administration of safe and effective antivenoms [14]. These are preparations of antibodies or antibody fragments generated from the plasma/serum of animals, usually horses, immunized with snake venoms $[15,16]$. When prepared following Good Manufacturing Practices (GMPs) and with the selection of appropriate venoms for immunization, antivenoms are safe and highly effective in the neutralization of the main manifestations of envenomings, especially those associated with systemic pathophysiological effects $[2,15]$. However, antivenom treatment poses a series of difficulties that need to be circumvented by novel developments and interventions that could improve and complement antivenoms in the therapy of envenomings. The main limitations of antivenom therapy are:

(1) Antivenoms need to be administered by trained medical and nursing staff in healthcare facilities under conditions that enable the management of potentially serious adverse reactions that may occur following their administration and whose incidence varies depending on the product $[17,18]$. In settings where long distances exist between the locale of the bite and the nearest healthcare facility, there is a significant delay in receiving antivenom. It has been shown that the time lapse between the bite and accessing medical treatment is strongly associated with the prognosis of the case, as demonstrated in rural settings in Sub-Saharan Africa, Asia, and Latin America, where such delays are common [19-22].

(2) While antivenoms are usually effective in halting the systemic manifestations of envenoming, such as bleeding, coagulopathies, cardiovascular disturbances, rhabdomyolysis, neuromuscular paralysis, and other systemic effects [2] if administered promptly after the bite, they are less effective in controlling the local manifestations of envenoming. These effects include edema, hemorrhage, myonecrosis, and cutaneous necrosis which develop rapidly around the bite site upon venom injection, as shown in experimental studies $[23,24]$. Hence, local envenoming can result in permanent tissue damage and disabilities of various types, especially when there is a delay in antivenom administration, generating an expanding wave of social suffering in families and communities $[2,25,26]$.

(3) Antivenoms are relatively expensive products and their availability and accessibility in developing countries is often limited due to various factors $[13,27]$. In addition, the distribution of antivenoms to rural health posts where most snakebites occur is commonly affected by administrative issues [28]. Antivenoms are often unavailable at the primary health level, hence resulting in people having to travel long distances to be treated in an appropriate setting $[21,29,30]$.

(4) Due to the immunological variation of snake venoms, antivenom specificity has an impact on the treatment of envenoming [31]. Antivenoms are generally effective against the venoms used for immunization and, through cross-neutralization, against venoms of closely related species [15]. However, there are medically relevant venoms for which effective antivenoms are not available in some regions. Furthermore, the immunogenicity of some clinically relevant toxins, such as the low molecular mass three finger toxins (3FTxs), is poor, making it difficult to raise antivenom of high titers against these components [32-34].

(5) Liquid antivenoms require a cold chain system for storage and distribution [15], which is often limited in developing countries, hence precluding the distribution of liquid products to rural health facilities in some regions. 
Animal-derived antivenoms will remain the centerpiece in the treatment of snakebite envenoming, at least in the short-medium term, and renewed efforts should be fostered towards improving their design and quality, the volume of antivenom made globally available, the procurement and distribution of antivenoms to regions of high snakebite incidence, and the training of medical and nursing personnel in the use of these products along the priorities set by the WHO strategy [13]. In addition, novel approaches aimed at new therapeutic alternatives are being considered. For example, the introduction of recombinant antibody technologies for the development of next generation antivenoms is being pursued and promising experimental results have been reported since different antibody formats can be adapted to specific pharmacokinetic and pharmacodynamic needs [35-37].

At the same time, there is an urgent need for novel non-immunological therapies that would complement antivenoms in the management of this disease, as indicated in the WHO strategy [13]. The possibility of introducing therapies that could be administered in the field rapidly after the snakebite, with a good safety profile and without requiring specialized medical personnel, is being actively considered as a step forward in the management of envenomings [38]. An intensive search for safe and effective natural and synthetic toxin inhibitors and other alternative therapies is currently being carried out by many groups at the preclinical level. Some of the most promising advances involve the repurposing of drugs developed by the pharmaceutical industry for other diseases. These drugs have undergone clinical trials and can inhibit key venom components, such as metalloproteinases (SVMPs) and phospholipases $\mathrm{A}_{2}\left(\mathrm{PLA}_{2} \mathrm{~s}\right)$. In addition, the development of novel high-throughput strategies for drug design could be applied to the snakebite field for the development of novel toxin inhibitors. The present review summarizes some of the most promising developments in this field and discusses issues that need to be considered for the effective translation of this knowledge to improve therapies for tackling snakebite envenoming.

\section{Identifying the Targets: How to Deal with the Complexity of Snake Venom Composition and Actions}

Snake venoms are complex secretions which are thought to have evolved in advanced snakes to facilitate prey capture [31,39-41], though snakes will also deploy these chemical weapons defensively, as exemplified by human snakebites. Our understanding of the complexity and evolutionary trends of snake venoms has been enriched by means of 'omic' technologies, which have provided a growing body of information in the fields of proteomics, transcriptomics, and genomics [40,42]. In addition to contributing to the study of venom evolution, ecology, biochemistry and toxicology, this wealth of data provides valuable insights into the design of more effective antivenoms and of novel snake venom toxin inhibitors [43]. In particular, the combination of proteomics and toxicological analyses, dubbed 'toxicovenomics' [41], now allows the identification of the most relevant toxins in particular venoms through the estimation of a Toxicity Score for individual toxins and venom fractions [44]. The assessment of the toxicity of venom fractions should evaluate not only overall toxicity, i.e., lethality, but also other relevant toxic activities of venoms such as hemorrhagic, procoagulant, myotoxic and dermonecrotic activities. The toxic profile to be tested depends on the main clinical effects of a particular venom.

The available information facilitates the classification of venom targets into four main categories, based on their toxicity and abundance in medically important snake venoms. These groups include components with: (a) high toxicity and high abundance, (b) high toxicity and lower abundance, (c) high abundance but lower toxicity, and (d) low abundance and low toxicity (Figure 1). In this classification, abundance refers to components which are present in many types of snake venoms, in variable proportion depending on the species. Consequently, we propose that the search for novel snake venom toxin inhibitors should be primarily focused on toxins of high toxicity and abundance (i.e., 'group a'), and especially on SVMPs, PLA 2 s and three-finger toxins (3FTxs), since they are by far the most abundant toxic components in venoms, with variations between families, and the ones playing key 
roles in the pathophysiology of most envenomings. The distribution and toxicological profiles of venom components will be discussed next.

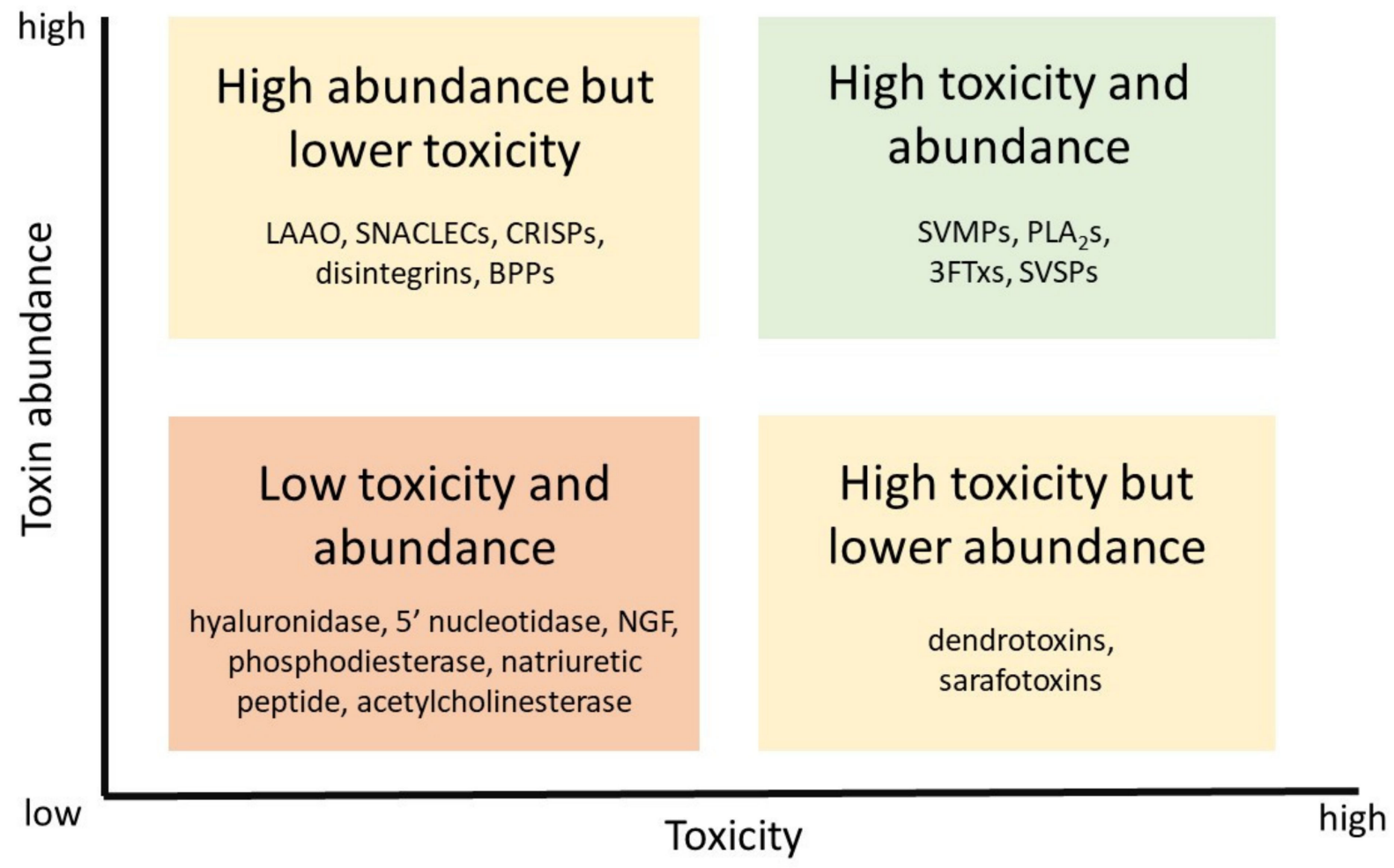

Figure 1. Distribution of snake venom toxins in four groups according to their abundance in venoms and their toxicity. Efforts to develop novel inhibitors should prioritize toxins of high abundance and toxicity, although for some venoms the search of inhibitors of toxins of high toxicity but lower abundance is also recommended. Owing to the intrinsic complexity of venoms, the design of the optimal mixtures of inhibitors should be based on venom composition. Abbreviations: LAAO: L-amino acid oxidases; SNACLECs: C-type lectin-like proteins; CRISPs: Cysteine-rich secretory proteins; BPPs: Bradykininpotentiating peptides; SVMPs: Snake venom metalloproteinases; $\mathrm{PLA}_{2} \mathrm{~s}$ : Phospholipases $\mathrm{A}_{2}$; 3FTxs: Three-finger toxins; SVSPs: Snake venom serine proteinases; NGF: Nerve growth factor. See text for details.

\subsection{Components of High Toxicological Impact and Abundance}

\subsubsection{Snake Venom Metalloproteinases (SVMPs)}

With few exceptions, SVMPs are abundant in viperid venoms, while present in lower amounts in elapid venoms, and in variable proportions in 'colubrid' (sensu lato) venoms [2,45-47]. SVMPs are sub-classified based on their domain composition [48]. Class PI comprises enzymes containing the metalloproteinase domain alone, while class PII includes representatives having a disintegrin domain in addition to the catalytic domain. In turn, class PIII SVMPs contain metalloproteinase, disintegrin-like and cysteine-rich domains. Within each class, there are subclasses encompassing dimeric or truncated variants [49].

SVMPs act on an ample spectrum of substrates, as revealed by proteomic and otheranalyses $[50,51]$. In terms of their pathophysiological effects, their actions on extracellular matrix components and on coagulation factors determine their ability to induce local and systemic hemorrhage, and coagulopathies, respectively [52]. Other effects induced by SVMPs include inflammation and pain [53], blistering and dermonecrosis [54], myonecrosis [55], and affecting skeletal muscle regeneration [56,57]. All these effects depend on the enzymatic activity of SVMPs, and therefore the search for inhibitors has generally focused on molecules that abrogate enzymatic activity. Thus, SVMPs play a key role in the overall pathology and pathophysiology of envenomings in viperid venoms. The precise role of PIII SVMPs present in elapid venoms is unknown, although they do not seem to contribute to their overall toxicity. 'Colubrid' (sensu lato) venoms contain PIII SVMPs known to in- 
duce hemorrhage and coagulopathy, and which are responsible for the systemic effects characteristic of the scarce severe envenomings caused by this group of snakes [58].

\subsubsection{Phospholipases $\mathrm{A}_{2}\left(\mathrm{PLA}_{2} \mathrm{~s}\right)$}

$\mathrm{PLA}_{2} \mathrm{~S}$ are ubiquitous components of snake venoms and they display a variety of toxic activities [59]. These enzymes catalyze the hydrolysis of the $s n-2$ ester bond in 1,2 diacyl-3-sn glycerophospholipids at the C-2 position by a mechanism dependent on conserved key residues at the catalytic site and the calcium-binding loop [60]. Elapid venom enzymes belong to group I PLA ${ }_{2} \mathrm{~S}$ [61], whereas viperid enzymes are classified as group II $\mathrm{PLA}_{2} \mathrm{~S}$ [62]. They share a similar catalytic mechanism but differ in their structure [60]. Many PLA 2 isoforms, particularly the acidic ones, are devoid of toxicity, whereas other isoforms, most of them cationic, show a diverse set of toxic effects, including neurotoxicity, myotoxicity, nephrotoxicity, edema-forming activity, anticoagulant activity, inhibition of platelet aggregation, hemolytic activity, and cardiovascular effects [59].

In many instances, the toxicity of $\mathrm{PLA}_{2} \mathrm{~S}$ is associated with molecular regions different from the catalytic site which enable these enzymes to bind to key targets in cells or coagulation factors in plasma [63]. Upon binding these 'acceptor' sites, the disruption of membranes or the inhibition of physiological functions may depend on the hydrolysis of phospholipids, while in other cases their action is based on catalytically independent processes. In addition, a subgroup of $\mathrm{PLA}_{2} \mathrm{~s}$, known as PLA $\mathrm{P}_{2}$ homologues, have substitutions in key catalytic residues, particularly in Asp 49 which is substituted by Lys and, in some cases, by Arg, Ser, or Asn [64]. These modifications render these isoforms catalytically inactive, while maintaining their toxic profile. The search for venom $\mathrm{PLA}_{2}$ inhibitors should aim to address both the inhibition of enzymatic activity (i.e., binding to the active site and the abrogation of the catalytic process), and blockage of the molecular sites that enable these toxins to bind to key targets.

\subsubsection{Three Finger Toxins (3FTxs)}

3FTxs are abundant components in elapid venoms and in many 'colubrid' venoms, but are seemingly absent from viperid venoms [46,47]. 3FTxs are low molecular mass proteins $(\sim 6-9 \mathrm{kDa})$, some displaying a quaternary structure, with a common 3D structure characterized by three loops emerging from a central core and several disulfide bridges [65]. There is a great variety of 3FTxs in snake venoms, which bind to a wide spectrum of targets and exert diverse toxicological effects $[66,67]$. The best-known representatives are the so-called $\alpha$-neurotoxins, which have a high affinity for the nicotinic cholinergic receptor located in the motor endplate of skeletal muscle fibers [68], and are responsible for the neuromuscular descending paralysis characteristic of envenomings by many elapid species, including terrestrial elapids and sea snakes $[2,69]$. Fasciculins are 3FTxs which inhibit acetylcholinesterase [70]. Still, some 3FTxs have evolved to bind to targets not related to the nervous system, such as clotting factors [71].

Another group of 3FTxs, which play an important role in envenomings by some terrestrial elapids of the genus Naja, includes the 'cytotoxins' or 'cardiotoxins'. They have the capacity to interact and disorganize cellular membranes, hence leading to plasma membrane damage and cytotoxicity [72,73]. These 3FTxs are the most abundant type of this toxin family found in Naja spp. venoms and, particularly in the case of many spitting cobra species, cause local cutaneous necrosis and myonecrosis [24,74]. Local necrosis is generally not well neutralized by antivenoms [24] and often leaves permanent sequelae in the victims [75].

3FTxs constitute a priority toxin group in the search for novel inhibitors because: (a) they are poorly immunogenic, owing to their low molecular mass, and hence complicate the development of high titres of neutralizing antibodies in animals immunized to generate antivenoms. In general, the potency of antivenoms raised against elapid venoms whose toxicity is mostly based on the action of 3FTxs is low, as compared to the potency of viperid antivenoms [76-78]. (b) In the case of cytotoxic 3FTxs, in addition to their poor 
immunogenicity, their effect on tissues upon injection has a rapid onset, hence making treatment with antivenom difficult [24]. This is especially the case when the time lapse between the bite and accessing health centers is delayed, as often occurs in Sub-Saharan Africa and Asia where cobras inflict a substantial number of bites.

\subsubsection{Serine Proteinases (SVSPs)}

Serine proteinases are widely present in snake venoms and display a variety of activities, some of which exert a role in envenomings, although their contribution is generally less relevant than that of SVMPs, PLA 2 s and 3FTxs. In addition to several activities described in vitro, i.e., kallikrein-like activity, activation of coagulation factor $\mathrm{V}$, protein $\mathrm{C}$ and plasminogen, and induction of platelet aggregation $[79,80]$, the most significant actions of SVMPs from a pathophysiological standpoint are the formation of fibrin from fibrinogen ('thrombin-like' activity, also known as 'pseudo-procoagulant activity') [81-83] and prothrombin activation [84,85]. The 'thrombin-like' activity results in the defibrinogenation characteristic of many viperid venoms. Despite its name, these SVSPs differ from endogenous thrombin in several ways, and they generate weak fibrin clots that are readily degraded by endogenous plasmin [81].

A relevant group of SVSPs in terms of human envenomings are group $C$ and group D prothrombin activators found in several Australian elapid venoms [85]. These enzymes induce a consumption coagulopathy associated with a drop in the concentration of several clotting factors and defibrinogenation, and contribute to coagulopathies and systemic bleeding described in envenomings by these Australian species $[84,86]$. Serine proteinases are also involved in cardiovascular alterations associated with increments in vascular permeability through the release of endogenous mediators from plasma proteins [79].

\subsection{Components of High Toxicity But Lower Abundance}

There are families of toxins of high toxicity which are distributed only in the venoms of certain snake species. Thus, they do not have the widespread relevance of the toxins described above but should be considered as targets for the development of inhibitors against envenomings by these species. One example are the dendrotoxins, characteristic of mamba venoms (genus Dendroaspis, family Elapidae). These toxins belong to the family of Kunitz-type proteinase inhibitors and act by blocking voltage-dependent potassium channels in neurons [87]. It is likely that some of the unique clinical manifestations of mamba snakebite envenomings [88] are induced by dendrotoxins. Thus, the search for mamba venom inhibitors should consider the inhibition of dendrotoxins.

Another example is the group of sarafotoxins present in the venoms of snakes of the genus Atractaspis (family Lamprophiidae, subfamily Atractaspidinae). These toxins are homologues of endogenous endothelins, and exert cardiotoxicity [89]. They play a significant role in the clinical manifestations of Atractaspis spp. snakebite envenomings, which include cardiac alterations [88]. Another component that may fit into this category is venom vascular endothelial growth factor (vVEGF). It has been suggested that vVEGF in the venom of Daboia russelii could play a role in the development of systemic capillary-leakage syndrome, a severe clinical manifestation in envenomings by this species in Asia [90,91]. Some rattlesnake venoms (genus Crotalus) contain low molecular mass myotoxins, a unique type of myotoxic components, which induce muscle contracture and vacuolization by acting on ion channels in skeletal muscle fibers [92], although the role of these toxins in rattlesnake envenoming is not clear.

\subsection{Components of High Abundance But Lower Toxicity}

Snake venoms contain proteins which are widely present in species of the Elapidae, Viperidae and 'Colubridae' (sensu lato) families, but which do not exert a highly significant role in the overall toxicity of envenomings, although some may play ancillary roles. This is the case of L-amino acid oxidase, for which several functions have been described in addition to its enzymatic activity [93]. However, its role in envenoming has not been 
proven to be significant. C-type lectin-like proteins (SNACLECs) are also common constituents of snake venoms and have been shown to exert anticoagulant activity in vitro, as well as diverse actions on platelets, such as aggregation, agglutination, and inhibition of aggregation [94,95]. In vivo, the most relevant action described for this group of venom proteins is thrombocytopenia, induced by C-type lectin-like proteins in some viperid venoms which induce von Willebrand factor-dependent platelet aggregation [96-98]. This effect contributes to the extent of systemic hemorrhage induced by SVMPs [97,98]. Clinical observations indicate that thrombocytopenia is associated with the frequency of systemic bleeding in envenomings by Bothrops species [99,100].

Disintegrins are venom components that bind to cellular integrins and derive from the proteolytic cleavage of PII SVMPs [101]. In vitro, some disintegrins inhibit platelet aggregation, but whether this also operates in the platelet hypoaggregation described for some viperid envenomings remains unknown. Cysteine-rich secretory proteins (CRISPs) are also widely present in snake venoms, although their possible toxic roles have not been demonstrated, despite their several pharmacological activities [102]. Pharmacologically active peptides, such as bradykinin-potentiating peptides (BPPs) are common constituents of viperid venoms, comprising in some cases a relatively high percentage of the venom proteome [46]. Despite their hypotensive action, which paved the way for the development of the potent hypotensive drugs captopril and enalapril [103], their actual role in envenomings remains dubious since injection of fractions rich in BPPs from one venom did not induce evident toxicity in mice [104].

\subsection{Components of Low Abundance and Low Toxicity}

Proteomic studies of snake venoms have identified several components which are present in some venoms at low concentrations, but do not seem to exert a relevant toxic role in envenomings. Examples are $5^{\prime}$ nucleotidase, phosphodiesterase, hyaluronidase, natriuretic peptides, ohanin-like peptides, disintegrin-like and cysteine rich (DC) fragments, acetylcholinesterase, nerve growth factor, and Kazal-type proteinase inhibitors, among others $[45,46]$. Future studies will uncover whether some of these components exert a role in the overall toxicity of some venoms, but no such evidence currently exists.

\section{Beyond the Direct Action of Toxins: The Need to Further Understand the Pathophysiology of Envenoming in the Search for Novel Therapies}

Snakebite envenoming occurs mostly through the direct action of venom toxins in cells, tissues, plasma, and the extracellular matrix, as described. However, envenomings also involve the generation of endogenous processes in the organism that contribute to the pathophysiology of envenomings. For example, the actions of toxins in tissues kick off cascades of inflammatory events and mediators which contribute to an increase in vascular permeability, pain, and systemic hemodynamic alterations [105,106]. Moreover, it has been proposed that the action of venoms on tissues results in the generation of abundant intracellular and extracellular Damage-Associated Molecular Patterns (DAMPs) or 'alarmins', which interact with cells of the innate immune system to expand the generation of mediators with multiple actions [107-109]. The concept of Venom-Associated Molecular Patterns (VAMPs) has been proposed, indicating that venom components themselves may directly activate cells of the innate immune system [110]. Understanding these endogenous pathways may pave the way for the design of therapeutic interventions aimed at reducing their deleterious consequences, for example by blocking the receptors or intracellular pathways that mediate the actions of DAMPs and VAMPs. Moreover, since envenomings are associated with the generation of reactive oxygen species (ROS) in the affected tissues, the use of antioxidant interventions has been proposed as an adjunct therapy [111] (Figure 2). 


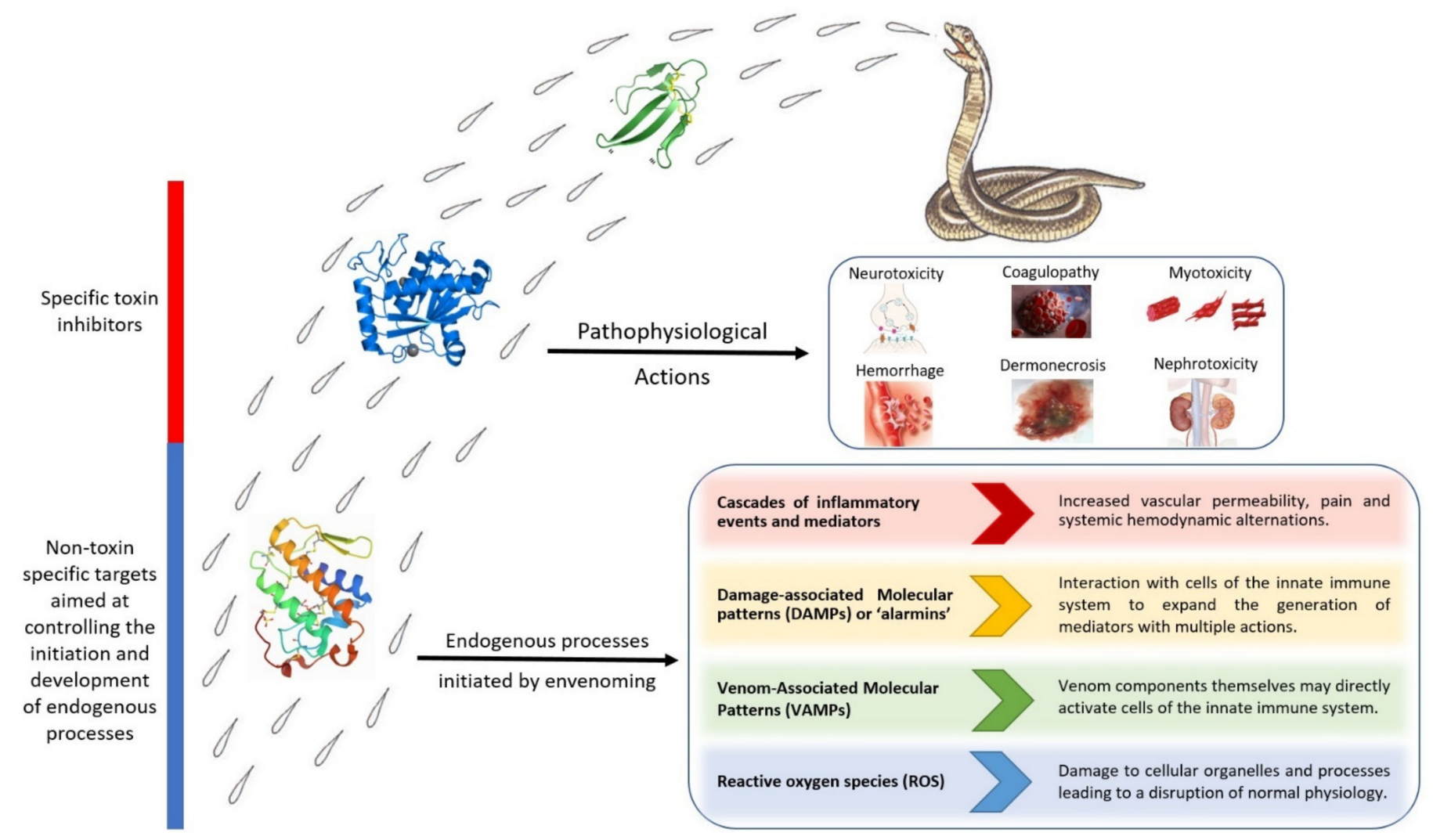

Figure 2. Snakebite envenomings are complex pathophysiological conditions that involve the direct action of venom toxins and the onset of endogenous processes secondary to the actions of toxins. Venoms contain toxins that directly cause neurotoxicity, myotoxicity, dermonecrosis, cardiovascular alterations, coagulopathies, and renal toxicity, among other effects. Concomitantly, the actions of toxins in tissues and cells promote endogenous processes through the action of inflammatory mediators, damage-associated molecular patterns (DAMPs), stimulation of innate immune cells by venom toxins (VAMPs) and the generation of reactive oxygen species (ROS), all of which amplify the action of venoms in a complex interactive scenario. The search for novel drugs for the management of these envenomings should include inhibitors that directly block the action of toxins as well as therapeutics that modulate the endogenous processes in envenomings.

Interventions aimed at reducing the action of venom components, without directly interfering with the toxins, include the use of cholinesterase inhibitors, such as neostigmine, in the case of venoms whose mechanism of action is based on the blockade of the nicotinic acetylcholine receptor ( $\mathrm{AAChR}$ ) by $\alpha$-neurotoxins, hence increasing the concentration of acetylcholine at the synaptic cleft [112-114]. Furthermore, therapeutic interventions may be directed towards improving the regenerative capacity of affected tissues and cells. This is the case of NUCC-390, an agonist of CXCR $_{4}$ receptor, which promotes the regeneration of nerve terminals affected by neurotoxic PLA $\mathrm{PL}_{2} \mathrm{~s}$ that act presynaptically [115], or possible therapies to improve skeletal muscle regeneration after venom-induced myonecrosis $[116,117]$. Hence, the in depth understanding of venom composition, the mechanisms of action of the most relevant toxins, and the pathophysiology of envenomings will provide valuable information not only for the design of specific toxin inhibitors, but also for other interventions aimed at controlling endogenous pathways playing a role in envenoming.

\section{The Search for Inhibitors: General Considerations}

As indicated above, animal-derived antivenoms are, and will continue to be in the coming years, the mainstay therapeutic for treating snakebite envenoming $[2,15]$. However, owing to some limitations of these immunobiologicals, alternative venom inhibitors of various origins are being sought as complementary therapies, some of which could be applied in the field rapidly after the onset of envenoming. These novel therapies include 
recombinant antibodies with high affinity for specific toxins, which can be engineered to provide improved pharmacokinetic profiles and safety, as in the case of humanized antibodies. The topic of recombinant antivenom antibodies has been dealt with in recent reviews $[36,118]$ and will not be considered further here, as the focus of this review is on natural and synthetic inhibitors distinct from antibodies.

A key aspect in the search for novel inhibitory compounds involves testing their inhibitory capacity. The most traditional way to test whether a compound can inhibit the action of venoms or purified toxins is through 'preincubation-type assays'. These involve the incubation of venom (or toxin) with the inhibitory molecule for a period (generally $30 \mathrm{~min}$ ) before testing the mixture in the corresponding experimental settings (e.g., both in vitro and in vivo), which vary depending on the effect being evaluated. This is also the method recommended by the WHO for the preclinical in vivo assessment of antivenom efficacy, which is then expressed as the Median Effective Dose $\left(E_{50}\right)$, i.e., the ratio venom (or toxin)/antivenom in which the effect of venom (or toxin) is inhibited by $50 \%$ [2,15]. A similar method can be used to assess the inhibitory potential of various compounds.

Despite the widespread use of this methodology, it has the caveat that it does not reproduce the actual circumstances of an envenoming, whereby venom is injected first and the treatment is provided at a later stage. Hence, it has been argued that a more appropriate evaluation of inhibitors (and probably also of antivenoms) should be based on 'rescue assays', in which the venom is injected first, and the inhibitors are administered at various time intervals after envenoming by using a route of administration that would model the actual route to be used in a clinical case, i.e., intravenous, intramuscular, subcutaneous, or oral [119]. This alternative setting takes into consideration the toxicokinetics of venoms (or toxins) and the pharmacokinetics of the inhibitor and considers possible actions of the inhibitors not necessarily related to direct interaction with toxins. However, it should be noted that such models require further development, as high venom dosing to generate rapid experimental endpoints (i.e., within $24 \mathrm{~h}$ ) provide considerable challenges to observing therapeutic efficacy in such models. Nonetheless, it is desirable that the search for novel venom or toxin inhibitors should include both types of assays, to gain a more complete understanding of the therapeutic potential of the compound of interest.

Another aspect that has gained attention in recent years is the convenience to search for inhibitory molecules within the arsenal of molecules already developed for other diseases, i.e., those which have gone through preclinical testing assessing their safety and efficacy, or even through phases of clinical testing; indeed, some of these are already being used in a clinical setting in the treatment of other pathologies. This drug repurposing or repositioning strategy will save considerable time and resources during downstream development steps. Thus, in addition to the development of completely novel inhibitors against snake venom toxins, the testing of drugs already developed by pharmaceutical research is a highly promising avenue in the field of snakebite envenomings.

\section{Inhibitors of Snake Venom Toxins}

There is extensive literature on natural and synthetic substances with the capacity to inhibit snake venoms and toxins. The general types of inhibitors will be presented, with a summary of their chemical features and their inhibitory potential. The information presented here is not exhaustive but aims to provide the key aspects of the various types of inhibitors and the evidence supporting their potential for snakebite envenomings.

\subsection{Inhibitors from Natural Sources}

\subsubsection{Secondary Metabolites of Plants}

Plants have been used for centuries in traditional medicine for treating snakebite envenoming all over the world and constitute a rich source of secondary metabolites that could inhibit venoms and toxins. There is abundant literature on plant-derived extracts or compounds isolated from species from all continents, with the capacity to inhibit specific toxic venom activities [120-125]. Most studies have been performed using crude 
plant extracts, while fewer publications described the isolation, structural characterization, and inhibitory potential of purified compounds. Predominantly, preincubation efficacy protocols have been followed, with fewer studies using rescue assays. Variable results have been obtained when using these different protocols and, generally, efficacy is reduced when extracts or isolated compounds are administered after envenoming [126-128]. In some cases, a different protocol has been used based on the administration of the extract before envenoming, simulating a situation in which people ingest the extract prior to going into settings at risk of snakebites $[125,129]$. Several secondary metabolites with inhibitory activities against venoms or toxins have been identified, including flavonoids, coumestans, phenolic compounds, pterocarpans, alkaloids, steroids, terpenoids, and tannins, among others [120-124]. A detailed analysis of this subject is beyond the scope of this work, but interested readers can consult several reviews [120-122,124].

Valuable information can be gathered using an ethnographical approach, based on the knowledge generated in popular medicine in different cultural contexts. This demands close communication between scientists and communities where this knowledge has been developed, conserved, and used [128,130,131]. This rich body of information provided at the community level can bring valuable insights in identifying species of plants, and the specific components of these plants, that hold potential venom-inhibitory compounds.

Thus, there are two main avenues in the study of the inhibitory potential of plants for snakebite envenoming (Figure 3). One involves the replication of practices followed in local communities using plant extracts. The idea is not to purify the inhibitory compounds, but instead to use the whole extracts in the same way that they are prepared in traditional medicine, reproducing in laboratory animals the methods followed in the community for preparing and administering these extracts. The use of whole extracts allows for the detection of synergism between different components. A more advanced stage in this strategy would be to use the extracts in clinical trials in humans, according to traditional practices and following standard bioethical procedures for clinical research. There have been few scientific evaluations of the efficacy of plant extracts in humans [132], an area that requires strengthening, providing that robust preclinical evidence of efficacy and safety has been previously generated. This line of research could validate, in scientific terms, the traditional uses of some plants in the management of snakebite envenoming.

The other avenue in the study of plants as venom antidotes follows the traditional pharmaceutical route, which involves the study of the extract in controlled experimental systems, followed by the isolation and structural characterization of the active principle(s). Such molecules are then chemically modified to improve their efficacy, safety, and pharmacokinetic properties, leading eventually to the development of a new venom inhibitory drug. Several studies have identified and characterized active principles from plants which inhibit various types of toxins. In few instances, the structural characterization of the inhibitor-toxin complex has been described via crystallography, as in the case of aristolochic acid [133], rosemarinic acid [134], and caffeic acid [135]. Moreover, docking and molecular dynamics simulations have also been used to analyze the interaction of plant-derived metabolites with snake venom PLA ${ }_{2} \mathrm{~S}$ and SVMPs [136-138]. Despite abundant research in the field of plant extracts and snake venoms, to the best of our knowledge no venom-inhibitory drug derived from a plant secondary metabolite has been approved so far for clinical use in the treatment of snakebite envenomings. 


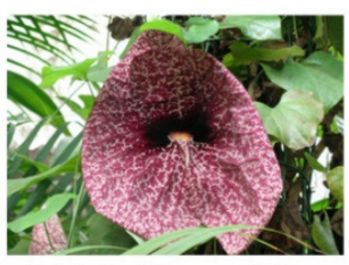

Aristolochia grandiflora

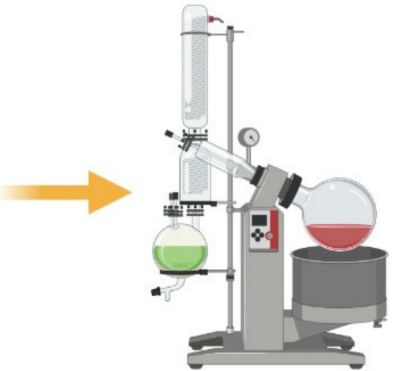

Preparation of extracts
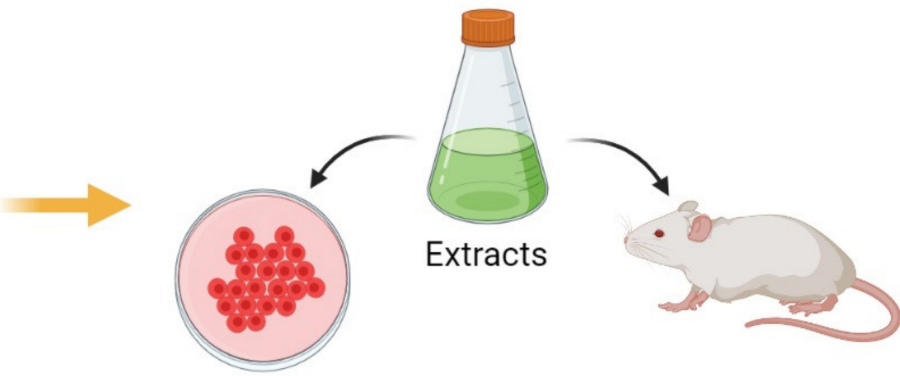

Testing of the extracts in the laboratory using in vitro and in vivo protocols
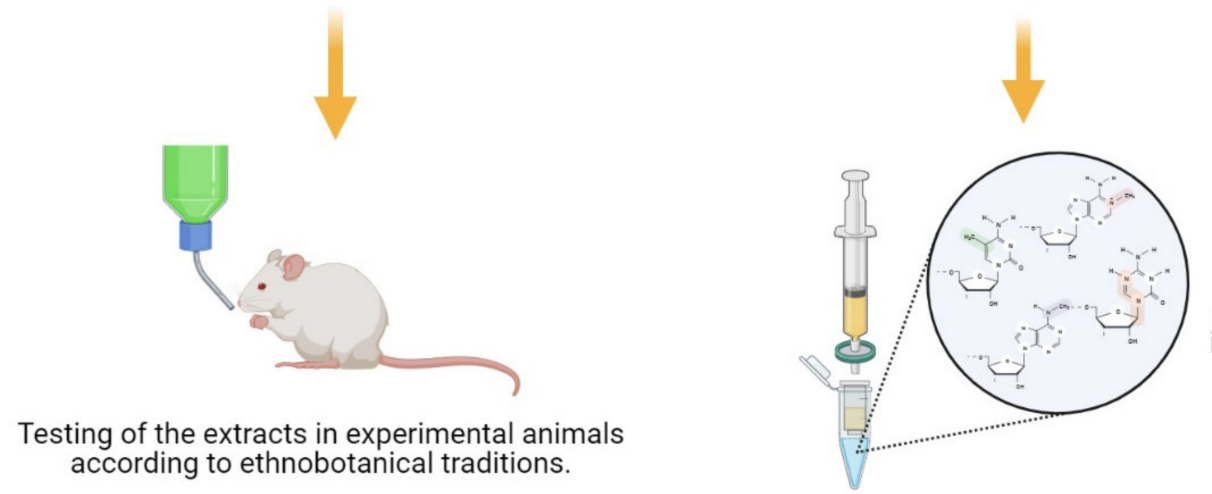

Fractionation of extracts and identification of secondary metabolites with inhibitory activity on venoms and toxins

Figure 3. The two main avenues to assess the inhibitory potential of plant extracts and other natural products against the action of snake venoms. Extracts can be tested for their inhibitory action in preclinical models. Extracts that yield positive results can be fractionated and the secondary metabolites responsible for inhibition are characterized and used as lead compounds for further pharmaceutical development. On the other hand, plant extracts can be tested in experimental animal models, on the basis of ethnopharmacological knowledge, by following the way extracts are prepared and administered according to popular traditions. The plant Aristolochia grandiflora is a source of molecules with inhibitory potential against various snake venom toxins. Created with BioRender.com.

\subsubsection{Animal Plasma Proteins}

Protein inhibitors of SVMPs and venom $\mathrm{PLA}_{2} \mathrm{~s}$ are present in the plasma of several animal species and constitute an innate immune mechanism to resist the action of venoms [139]. SVMP inhibitors belong to several families of proteins, such as the cystatin superfamily (in the plasma of snakes), the immunoglobulin superfamily (in the plasma of opossums and other species), the ficolin/opsonin P35 family (in the plasma of a hedgehog), and other types of inhibitors from snakes and rodents $[139,140]$. Their inhibitory capacity is generally based on the formation of non-covalent complexes with SVMPs, although the precise structural determinants responsible for binding have not been elucidated.

The PLA 2 inhibitors present in the plasma of snakes have been classified into three groups: $(\alpha)$ proteins with a $C$-type lectin-like structure, including a carbohydrate recognition domain, $(\beta)$ proteins with leucine-rich repeats, and $(\gamma)$ proteins with a three-finger motif [141]. All form non-covalent complexes with venom PLA 2 s. A PLA 2 inhibitor belonging to the immunoglobulin superfamily is present in the plasma of an opossum species. It inhibits the myotoxic and cytotoxic activities of a myotoxic PLA 2 and $\mathrm{PLA}_{2}$ homologue from $B$. asper venom, while not inhibiting the catalytic activity of an Asp49 myotoxic PLA 2 [142]. As with SVMP inhibitors, the structural details of PLA $\mathrm{P}_{2}$ inhibition by these proteins remains largely unknown. The identification of the molecular regions responsible for enzyme binding and inhibition may pave the way for the synthesis of inhibitory peptides that could eventually be useful in the treatment of envenomings by abrogating the action of these two types of venom components. 


\subsubsection{Mast Cells and Their Products}

It has been demonstrated that mast cells constitute an innate immune mechanism to counteract the toxicity of venoms produced by various animals, including snakes $[143,144]$. This is based on the action of mast cell proteinases, especially tryptase, which selectively cleaves venom toxins [145]. In addition, heparin, another mast cell-derived substance was shown to inhibit myotoxic and cytotoxic toxins in viperid venoms $[146,147]$. It was proposed that human recombinant tryptase $\beta$ could be used to treat snakebite envenomings by administering it at the site of venom injection, hence detoxifying venom components in situ. The potential use of tryptase $\beta$ and of heparin in snakebite envenoming awaits further experimental and clinical studies.

\subsection{Synthetic Inhibitors}

\subsubsection{Metalloproteinase Inhibitors}

Endogenous zinc-dependent metalloproteinases belonging to the superfamily of metzincins (MMPs, ADAMs and ADAMTs) play a wide variety of physiological roles and are involved in several pathophysiological conditions, including cancer, arthritis and other inflammatory conditions, pulmonary disease, and sepsis [148-151]. Thus, an intensive search for inhibitors of endogenous metalloproteinases has taken place during the past few decades. The first inhibitors of MMPs were based on the combination of a peptidomimetic moiety, resembling the sequence of natural substrates of these enzymes, and a zinc-binding motif which, initially, was based on hydroxamate groups which interact with the zinc in a bidentate model [152]. These first-generation inhibitors, such as batimastat and marimastat, showed Median Inhibitory Concentrations $\left(\mathrm{IC}_{50}\right)$ values in the nanomolar range and were considered promising candidates for clinical trials. The results of these trials, however, were disappointing, mostly because of poor bioavailability, lack of specificity for selective MMPs and, consequently, the occurrence of side effects [153,154]. These early failures led to the development of novel inhibitors of higher selectivity to specific MMPs, mostly based on the synthesis of groups adapted to the geometry of the variable $\mathrm{S1}^{\prime}$ pocket of different MMPs, and on the use of chelating moieties with lower zinc affinity [152]. An alternative approach has involved the search for inhibitors that block exosites in the hemopexin-like domain of MMPs instead of acting on the catalytic site [155].

Owing to the structural similarity in the catalytic site between SVMPs and MMPs, both members of the metzincin superfamily, a 'piggy-back' approach has been implemented in the field of snakebite in search for SVMP inhibitors, taking advantage of the enormous body of work done in the field of MMP inhibitors. Interestingly, the issues of low specificity and side effects described for some MMP inhibitors do not represent a problem in the field of SVMP inhibition because (a) having low specificity would guarantee inhibition of SVMPs in different venoms with different structural features at the S1' site, and (b) the side effects described in clinical trials result from the repeated administration of inhibitors over long time periods required for the treatment of chronic conditions, whereas in the case of snakebite envenoming, administration (whether single or multiple dosing) would likely be restricted to the first $24-48 \mathrm{~h}$ post-envenoming due to the acute nature of the clinical manifestations of this neglected tropical disease. Therefore, it is expected that, in the application of metalloproteinase inhibitors to SVMPs, lack of specificity would be desirable. Indeed, some of the first generation MMP inhibitors, such as batimastat and marimastat, have yielded positive results in preclinical models of envenoming following the administration of viperid venoms and purified SVMPs [156-159]. Marimastat has the advantage over batimastat in that it has a better bioavailability profile owing to its solubility, which allows for oral administration [152].

The possible use of chelating agents, in clinical use for the treatment of metal intoxication, such as $\mathrm{CaNa}_{2}$ EDTA, 2,3-dimercapto-1-propanesulfonic acid (DMPS), dimercaprol (British anti-Lewisite), and tetraethyl thiuram disulfide (Disulfiram), have also been assessed in experimental animal models of envenoming, with positive results [157,160-162]. However, because these molecules essentially work by chelating the zinc ion, without 
having a moiety that interacts with residues at the catalytic site, their in vitro SVMP inhibitory potency is lower when compared to peptidomimetic inhibitors [157,159]. Despite this observation, the metal chelator DMPS exhibited impressive in vivo neutralization of the local and systemic effects of SVMP-rich venom from the saw-scaled viper Echis ocellatus, including outperforming marimastat in a pre-incubation model of envenoming, and providing protection against lethality when delivered post-venom delivery, including when dosed orally $[159,161]$. These findings, coupled with DMPS already being a licensed medicine and exhibiting good oral bioavailability, make it a strong candidate for transition into clinical trials for the treatment of snakebite. Other chelating agents that have shown efficacy against SVMPs in pre-incubation experiments are the biphosphonate clodronate and the tetracyclyne doxycycline [163]. Figure 4 depicts the structures of some of the SVMP inhibitors that have been preclinically tested. A novel approach for generating SVMP inhibitors is based on the engineering of a biomimetic of endogenous tissue inhibitors of metalloproteinases (TIMPs) by introducing three binding elements in a synthetic tetrapolymer [164]. An unexplored but interesting possibility is the search for molecules that could interfere with exosites in SVMPs, particularly in the case of PIII SVMPs which exert systemic effects. However, this possibility awaits for the identification of exosites in the disintegrin-like and cysteine-rich domains of these SVMPs.

\subsubsection{Phospholipase $A_{2}$ Inhibitors}

The $\mathrm{PLA}_{2} \mathrm{~S}$ constitute a large superfamily of enzymes classified within several groups and subgroups that belong to six main types [165]. One of these groups includes secretory $\mathrm{PLA}_{2} \mathrm{~S}$, which comprises a large collection of enzymes of 14-18 kDa containing 6-8 disulfide bonds. Secretory $\mathrm{PLA}_{2} \mathrm{~s}$ belong to ten different groups which play relevant roles in physiological and pathophysiological processes [165]. Group IB PLA ${ }_{2} \mathrm{~s}$ are present in pancreatic secretions and have a digestive role, whereas group IIA PLA ${ }_{2} \mathrm{~S}$ are expressed in high concentrations in inflammatory exudates and have been associated with diverse disease conditions such as cancer, arthritis, atherosclerosis, and cardiovascular disease [166]. The inflammatory role of group IIA PLA $\mathrm{S}_{2} \mathrm{~S}$ is related to their ability to cleave arachidonic acid in phospholipids, which is then used in biosynthetic pathways to generate eicosanoids, i.e., prostaglandins, leukotrienes and thromboxanes which exert multiple inflammatory actions [167].

Secretory $\mathrm{PLA}_{2} \mathrm{~S}$ are abundant in snake venoms, often comprising a significant portion of their proteomes [2,45]. As in the case of metalloproteinases, the similar catalytic mechanism of human and venom PLA $\mathrm{A}_{2} \mathrm{~s}$ allows for the possibility of using inhibitors developed for human enzymes as potential inhibitors of venom enzymes. University and industrial laboratories have searched for potent $\mathrm{PLA}_{2}$ inhibitors, aimed at treating clinical conditions where $\mathrm{PLA}_{2} \mathrm{~S}$, especially inflammatory group IIA $\mathrm{PLA}_{2} \mathrm{~s}$, play a key role in pathophysiology. Examples of such synthetic inhibitors include sulfonamides, amides, oxadiazolones and indoles [165].

The most promising inhibitors of human group IIA PLA 2 are the indoles LY315920 (Varespladib) and its prodrug LY333013 (methyl Varespladib) [166,168]. These drugs have been tested in clinical trials for rheumatoid arthritis, sepsis, and cardiovascular disease [169-171]. Although, for several reasons, the clinical use of these drugs was abandoned following phase II and phase III clinical trials, recent studies suggest that they can be repur-

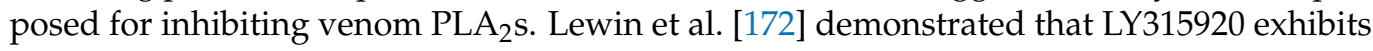
broad spectrum inhibition of $\mathrm{PLA}_{2}$ activity in many viperid and elapid snake venoms. Rescue-type experiments evidenced the ability of LY315920 and LY333013 to prevent or delay death in mice and piglets envenomed with lethal doses of potent neurotoxic elapid venoms whose mechanism of toxicity is based on the presynaptic action of neurotoxic $\mathrm{PLA}_{2}$ s [173-175]. LY315920 was able to prevent the development of the neuromuscular blockade induced by Oxyuranus scutellatus venom in nerve-muscle preparations ex vivo. When the inhibitor was added to the preparation after venom, it was effective at abrogating venom-induced blockade at times when antivenom is ineffective [176]. 
LY315920 was also effective in inhibiting the cytotoxic effect of the venom on C2C12 myotubes and reducing local myonecrosis induced by crude venoms and myotoxic $\operatorname{PLA}_{2} \mathrm{~S}$ from the venoms of two viperids and one elapid, even when administered after venom injection [177]. Moreover, this inhibitor also reduced the extent of local tissue damage and improved muscle regeneration in experimental envenomings by Deinagkistrodon acutus [178]. $\mathrm{PLA}_{2} \mathrm{~s}$ exert anticoagulant activities owing to the hydrolysis of phospholipids which are required for blood clotting or by directly binding to some clotting factors [179]. LY315920 has been shown to inhibit the anticoagulant activity of a variety of snake venoms by inhibiting $\mathrm{PLA}_{2}$ activity [180-183].

\section{SVMP - metal chelators}

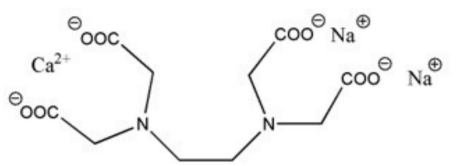

$\mathrm{CaNa}_{2}$ EDTA<smiles>O=S(=O)(O)CC(S)CS</smiles>

DMPS<smiles>CCN(CC)C(=S)SC(=S)N(CC)CC</smiles>

Disulfiram<smiles>OCC(S)CS</smiles>

Dimercaprol

\section{SVMP - hydroxamate peptidomimetics}

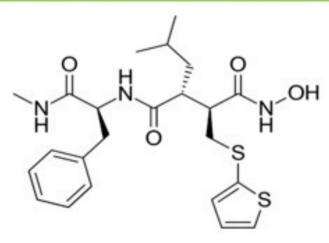

Batimastat<smiles>CNC(=O)[C@H](NC(=O)[C@H](CC(C)C)[C@H](O)C(=O)NO)C(C)(C)C</smiles>

Marimastat

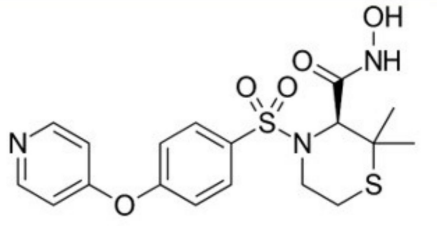

Prinomastat

\section{PLA2 inhibitors}

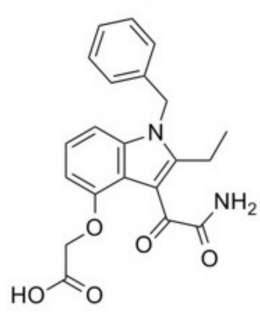

LY315920 (Varespladib)<smiles>CCc1c(C(=O)NC(N)=O)c2ccccc2n1Cc1ccccc1</smiles>

LY333013 (Methyl-Varespladib)

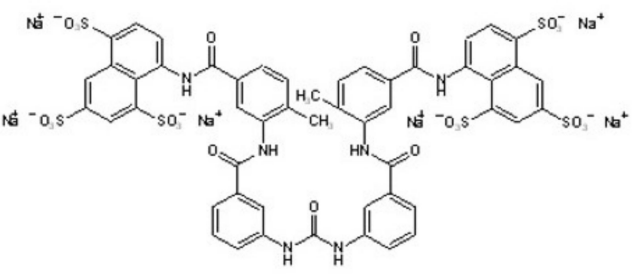

Suramin

Figure 4. Structures of some of the synthetic compounds that have shown inhibitory activity against snake venoms toxins. Inhibitors of SVMPs include chelating agents, which work by removing the zinc atom of the catalytic site of these enzymes, and hydroxamate peptidomimetics which, in addition to having a chelating moiety (hydroxamate), contain a peptidic sequence that fits within the catalytic region of these enzymes. PLA 2 inhibitors include Varespladib and its methyl-derivative, and the antiparasitic drug suramin.

In addition to catalytically active Asp49 $\mathrm{PLA}_{2} \mathrm{~s}$, viperid venoms contain $\mathrm{PLA}_{2}$ homologues characterized by substitutions at residue 49 (Asp substituted by Lys or other residues) and in the calcium binding loop, which render these proteins enzymatically inactive [64]. Despite their lack of catalytic activity, these homologues are myotoxic, and induce pain and inflammation [184-186]. Interestingly, LY315920 partially inhibits myotoxicity in vivo and cytotoxicity on $\mathrm{C} 2 \mathrm{C} 12$ myoblasts in culture induced by these homologues, suggesting that this inhibitor is also effective against these isoforms. The structural analysis 
of the binding of LY315920 to a Lys49 PLA 2 homologue indicates that it fits into the hydrophobic channel and binds to the His 48 and Lys49 residues. In addition, it also prevents the binding of the 'membrane disrupting site' of this myotoxin to its membrane target [187]. The glycosaminoglycan heparin inhibits the action of a myotoxic PLA $\mathrm{A}_{2} \mathrm{~s}$ homologue by interacting with cationic residues of the $\mathrm{C}$ - terminus, which are involved in the membranedestabilizing activity of this toxin [188]. Suramin, a polysulphonated synthetic compound used in the therapy of parasitic diseases, has also been shown to inhibit the myotoxic and cytotoxic activities of Lys49 PLA $_{2}$ homologues, and the structural basis of the interaction of these myotoxins with suramin has also previously been investigated [189-191]. Figure 4 depicts the structures of some PLA $\mathrm{P}_{2}$ inhibitors that have been tested against snake venoms in preclinical studies.

\subsubsection{Serine Proteinase Inhibitors}

Although serine proteinases are less relevant, as compared to SVMPs and $\mathrm{PLA}_{2} \mathrm{~s}$, in the overall toxicity of snake venoms, in some cases they display relevant toxic activities that should be counteracted in the treatment of envenomings. The search for venom serine proteinase inhibitors has received much lower attention than that for SVMP and PLA 2 inhibitors. As in the former case, the most effective strategy is the repurposing of drugs which inhibit these enzymes that have been developed for treating other pathologies.

One of the few studies involving snake venoms using a serine proteinase inhibitor approved for human use, nafamostat, showed that, despite inhibition of SVSP activity in vitro, it did not provide protection against the lethal effects of Echis ocellatus venom, and that its addition to a mixture of SVMP and PLA 2 inhibitors did not improve the efficacy of the mixture in neutralizing the venom toxicity of five viperid species [159]. It remains to be determined whether serine proteinase inhibitors could be effective in the treatment of coagulopathies induced by venoms whose procoagulant activity is predominantly based on the activity of serine proteinases, such as some Australian elapids, and viperids like Crotalus durissus and Lachesis spp. [84,192,193]. One issue to consider when using serine proteinase inhibitors designed to inhibit human enzymes is the potential side effects of such inhibitors, especially regarding their anticoagulant effects in the context of envenomings characterized by coagulopathies. Thus, in contrast to the generic inhibitors proposed above for SVMP and $\mathrm{PLA}_{2}$ toxins, the design of inhibitors with specificity towards SVSP venom enzymes is recommended to avoid undesirable off target effects.

\subsubsection{Three Finger Toxin Inhibitors}

One of the greatest challenges in the design of inhibitors for the therapy of snakebite envenomings relates to the inhibition of 3FTxs, which are particularly abundant in elapid venoms and responsible for neurotoxicity (i.e., neuromuscular paralysis) and cytotoxicity (i.e., tissue damage). The strategy of repurposing drugs developed for other human diseases, quite useful in the case of SVMP and PLA 2 inhibition, does not apply in the case of 3FTxs due to their unrelatedness to human drug targets and, therefore, novel drugs need to be designed to attain this goal. Fortunately, there are methodological platforms that allow the development of potentially effective inhibitors. A few possibilities are discussed next.

Post-synaptically acting $\alpha$-neurotoxins of the 3FTx family bind with high affinity to $\mathrm{nAChRs}$ at the motor endplate of skeletal muscle fibers, inducing a blockade in neuromuscular transmission and a life-threatening flaccid paralysis [194]. A decoy receptor approach, using mimotopes synthesized based on recombinant humanized nAChR subunits, has been proposed and preliminarily explored [195]. The binding of such mimotopes to neurotoxins would preclude their interaction with native receptors, hence abrogating their effect. One issue with this approach is that different $\alpha$-neurotoxins may bind to different sequences in the receptor. This could be circumvented by first identifying the most relevant $\alpha$-neurotoxins in a variety of venoms, through a toxicovenomic approach, and then recognizing the sequences or mimotopes of the receptor that bind these toxins. A high throughput methodology has been applied to address this issue, i.e., label-free bio-layer 
interferometry, which enables the study of the binding of different venoms and neurotoxins to various molecular regions of the receptor [196]. This has allowed the recognition of orthosteric and allosteric sites in the receptor responsible for neurotoxin binding [197]. The identification of these sites may lead to the synthesis of a diverse set of mimotopes that could bind and block a wide variety of $\alpha$-neurotoxins.

Another avenue for the design of 3FTx inhibitors is based on aptamers, i.e., short single stranded DNA or RNA oligonucleotides which show variable three-dimensional shapes and therefore present high versatility for binding different targets, including toxins $[198,199]$. High throughput methods have been implemented for the design and screening of aptamers that bind 3FTxs, such as $\alpha$-bungarotoxin from Bungarus multicinctus venom [200]. Aptamers designed to bind $\alpha$-bungarotoxin also interact with cytotoxins (cardiotoxins), other 3FTxs present in elapid venoms which cause tissue damage. These aptamers inhibited the membrane-disrupting activity of a cytotoxin [201]. Thus, the development of aptamers, ideally a mixture of oligonucleotides that could bind and inhibit a variety of 3FTxs, must be pursued as a therapeutic alternative to counteract the toxicity of these venom components. Similarly, high throughput screening of synthetic peptides is another alternative for the discovery of molecules that bind and block the action of 3FTxs [202].

Another promising strategy in the search for 3FTx inhibitors relies on the design of synthetic nanoparticles with the ability to bind and inhibit specific venom components [203]. Abiotic synthetic hydrogel nanoparticles were designed through an iterative process of 'directed chemical evolution' and showed a broad spectrum of interaction with 3FTxs and $\mathrm{PLA}_{2} \mathrm{~s}$ from a variety of elapid venoms [204]. These nanoparticles were effective at inhibiting the cytotoxic effect of the necrotizing cobra venoms of Naja nigricollis and $N$. mossambica on a myogenic cell line and inhibited the dermonecrotic activity of $N$. nigricollis venom in mice. This inhibition was observed not only in experiments where nanoparticles and venom were incubated prior to injection, but also when nanoparticles were administered after venom injection [204]. Owing to the versatility of the interactions between nanoparticles and proteins, they constitute a promising alternative for the development of potent inhibitors of neurotoxic and cytotoxic 3FTxs, and of other toxins as well. Figure 5 summarizes the various options being explored to develop inhibitors of 3FTxs.

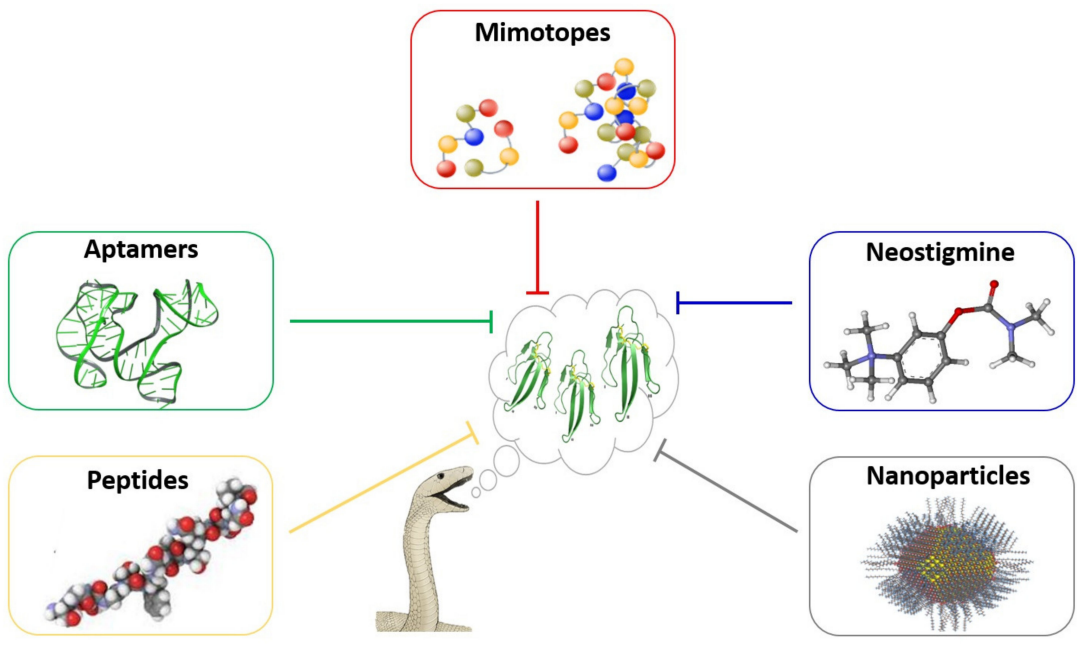

Figure 5. Possible sources of inhibitors against the family of 3FTxs, abundant in elapid snake venoms and responsible for neurotoxicity and cytotoxicity. Aptamers, peptides, and nanoparticles can be designed as to bind with high affinity to these toxins. Likewise, mimotopes, with sequences of the receptors of these toxins, especially the nicotinic acetylcholine receptor, could block toxins' interacting sites with receptors. Neostigmine, albeit not being an inhibitor of neurotoxins, inhibits acetylcholinesterase at the neuro-muscular junction, thus increasing the local concentration of the neurotransmitter without directly blocking the toxin. 


\subsubsection{Inhibitors of Other Types of Toxins}

Depending on the venom, other types of enzymes and toxins may exert a role in envenoming and, therefore, inhibitors against these components may also warrant some attention as secondary targets after those described above. For example, hyaluronidase is a venom component which plays a role as a spreading factor through the degradation of hyaluronic acid in the matrix and is possibly involved in local tissue damage [205]. Several inhibitors of venom hyaluronidase have been described, such as aristolochic acid, alkaloids, flavonoids, sodium chromoglycate, and polysaccharides, among others [205,206]. Sodium chromoglycate and sodium auro-thiomalate were effective in reducing the local and systemic toxicity of two snake venoms [206]. Efforts have been also directed towards the search of LAAO inhibitors by repurposing FDA-approved drugs [207]. Moreover, the search for inhibitors against other non-enzymatic toxins, such as disintegrins, C-type lectinlike proteins and venom vascular endothelial growth factor, which exert toxic activities in some venoms, should be pursued.

\section{The Potential of Photobiomodulation Therapy for Snakebite Envenoming}

Photobiomodulation is a type of phototherapy that includes low-level laser (LLL) and light emiting diode (LED); it utilizes light wavelengths between 600 and $1000 \mathrm{~nm}$ to deliver radiation to tissues. It is a non-invasive form of phototherapy used in a variety of musculoskeletal diseases [208]. This therapeutic option has been explored at the experimental level for the treatment of local pathology induced by Bothrops spp. snake venoms (see review by Silva et al., 2018 [209]). These studies have demonstrated that these therapies, when applied after venom injection in animals, reduced venom-induced local effects such as edema [210,211], hyperalgesia [211,212], hemorrhage [213], and myonecrosis [211,214,215].

Despite these promising results, the mechanisms by which these therapies reduce venom toxicity in vivo are not clear at present. Evidence indicates that these do not depend on a direct effect of the light on the venom, since the irradiation of venoms before injection did not affect toxicity $[211,215]$. Therefore, the inhibitory effect is based on the action of light on tissue components, rendering them less susceptible to the venoms. When tested on a myoblast/myotube cell culture, LLL reduced snake venom cytotoxicity and increased myoblast differentiation into myotubes [216]. The mechanisms of inhibition of venominduced hyperalgesia have been also investigated [217]. Photobiomodulation reversed venom-induced mechanical hyperalgesia and allodynia and decreased venom-induced Fos expression, as well as the mRNA levels of IL-6, TNF- $\alpha$ and B1 and B2 kinin receptors. Since these forms of therapy are already in use in the clinic for several conditions, the possibility of designing and implementing clinical trials in envenomings by snakes that inflict significant local tissue damage would be a relevant task, and indeed such trials are being planned in Brazil (Stella R. Zamuner, personal communication).

\section{Towards the Introduction of Venom Inhibitors for Clinical Use: Priority Tasks in Preclinical Testing}

The search for novel natural and synthetic inhibitors of venom toxins, and the analysis of the inhibitory potential of known inhibitors, should continue and new options need to be explored. At the same time, priority actions are recommended for the repurposing of inhibitors that have already gone through phases of clinical testing for other pathologies, such as inhibitors of SVMPs (e.g., hydroxamate peptidomimetics, metal chelators) and PLA $\mathrm{A}_{2} \mathrm{~S}$ (e.g., Varespladib-LY315920). These are the most likely candidates to go through intensive preclinical and, eventually, clinical trials in snakebite envenomings. Previous studies with DMPS, batimastat and marimastat or LY315920 have demonstrated their efficacy for reducing the toxicity of SVMP-rich and PLA $_{2}$-rich venoms, respectively [157-159,161,175]. Furthermore, the combined use of SVMP and $\mathrm{PLA}_{2}$ inhibitors in a dosing regimen provided increased therapeutic efficacy than each inhibitor alone and prevented death in mice receiving lethal doses of five medically important viperid venoms [159], hence suggesting that this combination is likely to have broad inhibitory potential for viperid venoms. 
While such an approach is rational, as most viper venoms contain numerous SVMP and $\mathrm{PLA}_{2}$ toxin isoforms in abundant yet varying amounts, selection of the most appropriate inhibitor combination will require careful consideration, in terms of optimization of dosing and therapeutic potency, stable formulation of the distinct inhibitory components, and ensuring freedom from drug-drug interactions [38]. There are cases of medically relevant snake venoms whose inhibition may require the use of other substances in addition to SVMP and PLA 2 inhibitors. This demands a careful case-by-case analysis of the venoms to be inhibited. Ultimately, the selection of new snakebite inhibitors will initially require robust evidence of preclinical efficacy against envenoming, and thus some recommendations relating to the design of such studies are outlined below.

\subsection{The Design of Preclinical Experiments}

As previously discussed, in vivo studies for assessing venom inhibition must include not only experiments involving incubation of venoms and inhibitors prior to injection, but also rescue experiments whereby the inhibitors are administered at various time intervals after the injection of venom [119], as has been done in several studies [157-159,161] (Figure 6). The route of injection should be carefully considered. In the case of local tissue damage, administration of the inhibitors can be done at the site of venom injection, i.e., intramuscularly or subcutaneously. For practical reasons, the possibility of administering inhibitors by the oral route should be considered. This can be done in the cases of marimastat, DMPS, and the prodrug LY333013, which have good oral bioavailability [159,174]. Since the possibility exists of administering these inhibitors in the field, rapidly after a snakebite, the oral route is important to evaluate. Some inhibitors, like batimastat and LY315920, can be administered by the intravenous route as well, simulating a hospital setting. The inhibitor doses to be selected should be based on the estimation of the corresponding $\mathrm{IC}_{50}$ values, determined in preincubation experiments, and based on combined pharmacokinetic and pharmacodynamic evaluations performed in appropriate corresponding models, and/or on doses scaled to those that have been tested in human clinical trials. Experiments may also consider the combined use of inhibitors and antivenoms, hence resembling a situation where inhibitors are administered in the field, or even in the hospital, followed by the normal use of antivenom in a hospital setting $[159,174]$. This would evaluate whether there are synergistic, additive, or antagonistic interactions between inhibitors and antivenom.

\subsection{Pharmacokinetic and Biotransformation Issues}

Owing to the differences in chemical structure and molecular mass between venom components and synthetic inhibitors, there is likely a mismatch between venom toxicokinetics and inhibitor pharmacokinetics, an issue that must be carefully considered. Moreover, differences in inhibitor pharmacokinetics depending upon the route of injection should be also taken into consideration in the design and interpretation of experiments. There is a possibility that, owing to the effects of venoms on cardiovascular parameters, drug pharmacokinetics may vary in envenomed animals as compared to normal animals, an issue that also needs to be accounted for. Experiments should consider the need to use repeated doses of the inhibitors, owing to pharmacokinetic considerations. This has been shown in the case of LY315920 and LY333013 in a piglet model of envenoming by the coral snake Micrurus fulvius [174]. 

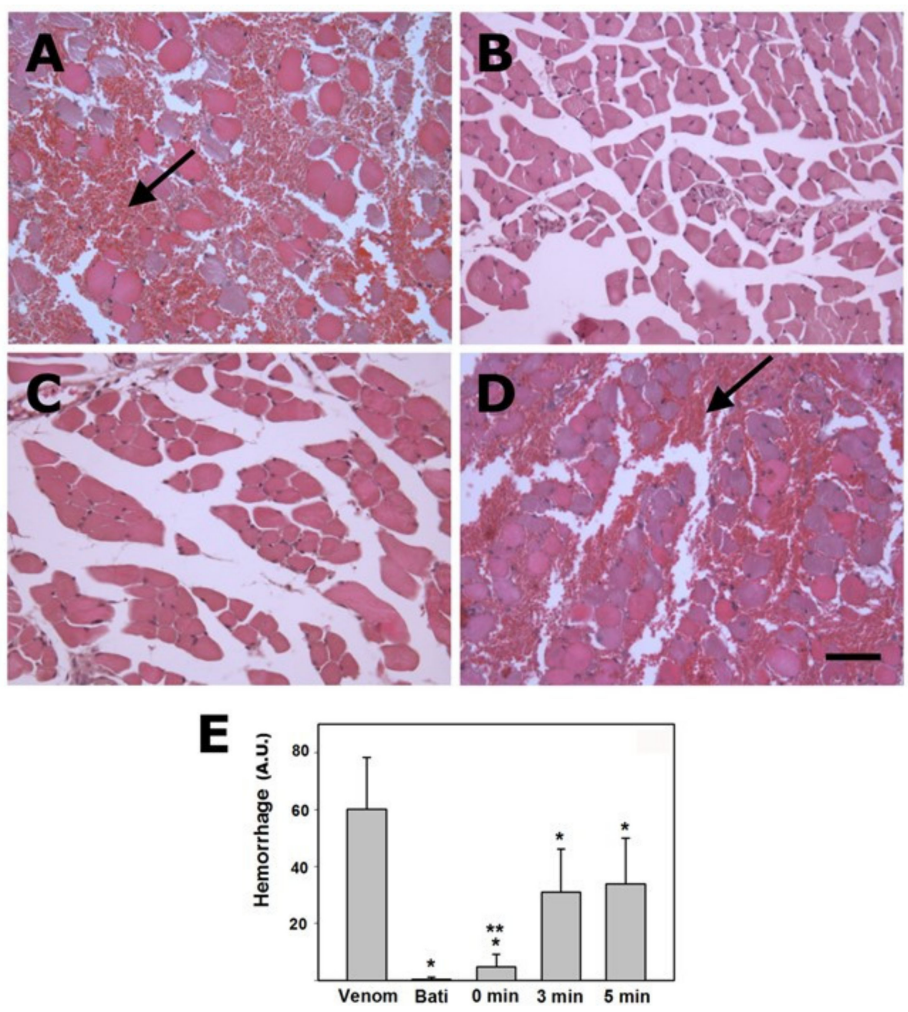

Figure 6. Inhibition by the hydroxamate peptidomimetic Batimastat of the local hemorrhagic activity of the venom of Echis ocellatus in muscle tissue of mice by a rescue-type experiment. (A) Injection of venom alone $(20 \mu \mathrm{g})$. Note the abundant local hemorrhage due to the action of SVMPs, as evidenced by masses of erythrocytes (arrow) in the interstitial space. (B) Injection of Batimastat alone; no effect is observed in muscle tissue. (C) Injection of venom $(20 \mu \mathrm{g})$, followed immediately by local administration of Batimastat. There is complete inhibition of hemorrhagic activity. (D) Injection of venom $(20 \mu \mathrm{g})$ followed by Batimastat $5 \mathrm{~min}$ after envenoming. There are areas of hemorrhage reflecting the rapid action of hemorrhagic toxins. All samples were collected $3 \mathrm{~h}$ after venom injection. (E) Quantification of hemoglobin in muscle tissue, as an index of hemorrhagic activity. Venom and Bati represent values in mice injected with venom alone (venom) and Batimastat alone (Bati). 0, 3 and $5 \mathrm{~min}$ represent values from mice injected with venom and then receiving Batimastat at either 0 , 3 or 5 min after envenoming. Results are presented as mean \pm S.D. $(n=4) .{ }^{*} p<0.05$ when compared to venom. ${ }^{* *} p<0.05$ when compared to $3 \mathrm{~min}$ and $5 \mathrm{~min}$. Reprinted from Arias et al. (2017), Toxicon 132: 40-49, copyright 2017, with permission from Elsevier.

The biotransformation of inhibitors is another issue to consider. This was highlighted in the case of batimastat and marimastat in the experimental envenoming with Echis ocellatus venom in mice. In the case of batimastat, the $\mathrm{IC}_{50}$ values for the inhibition of local (skin) and systemic (pulmonary) hemorrhage in preincubation experiments, were $0.36 \mu \mathrm{M}$ and $200 \mu \mathrm{M}$, respectively [158]. Since local hemorrhage is tested by injecting the venominhibitor mixture into the skin, whereas systemic hemorrhage is assessed by intravenous injection, such discrepancies suggest that, in the circulation, venom SVMPs may dissociate from the inhibitor or that the hydroxamate peptidomimetic drugs are degraded by plasma enzymes, such as esterases, or bind readily to plasma proteins [218].

\subsection{The Need to Assess Inhibition of Several Toxic Activities}

The combined use of SVMP and PLA 2 inhibitors is highly promising for the treatment of viperid envenomings, owing to the relevance of these enzymes in the overall pathology and pathophysiology of envenomings [159]. Since these envenomings are characterized by a complex series of deleterious effects, a detailed assessment of the potential usefulness of such inhibitory mixtures should consider not only the evaluation of the lethal activity, but 
also the analysis of inhibition of other relevant effects, i.e., local and systemic hemorrhage, local myonecrosis, in vitro procoagulant activity and in vivo defibrinogenating effect (see for example $[157,158])$. In some cases, such as with $D$. russelii venom, the inhibition of renal alterations and the systemic capillary leakage syndrome should also be evaluated. Such in-depth assessment provides robust evidence on the preclinical efficacy of the inhibitors to support the design of clinical trials. Figure 7 summarizes some of the main issues to be considered when undertaking the preclinical evaluation of venom inhibitors.

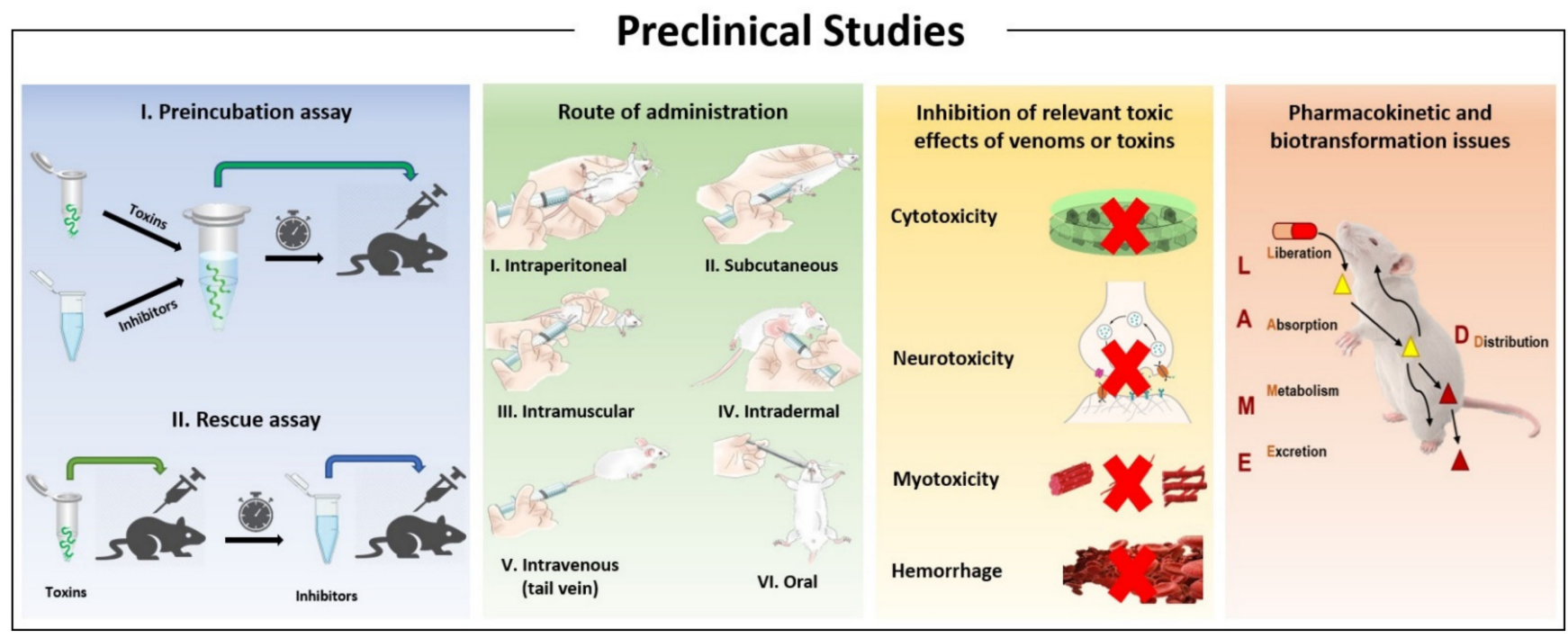

Figure 7. Issues that should be considered when designing experimental protocols to assess the preclinical efficacy of inhibitors against snake venoms or toxins. Experiments must include preincubation and rescue types of assays. The routes of administration of venoms and inhibitors should be chosen by trying to replicate the possible real-life scenario of envenomings. In addition to the study of inhibition of lethal effect of venoms and toxins, the inhibition of other toxicologically relevant activities should be considered, which vary depending on the venom or toxin. Finally, the pharmacokinetic and biotransformation aspects of a particular drug have to be taken into consideration as to adjust the route of injection, the dose, and the need of repeated doses of the inhibitor.

\section{The Final Goal: Design and Implementation of Clinical Trials for the Evaluation of Inhibitors as Therapeutics for Snakebite Envenoming}

The development and preclinical testing of inhibitors for the treatment of snakebite envenomings is a mounting task, but the final challenge has to do with the demonstration of efficacy and safety in clinical trials, an issue that is beyond the goals of this review. Nevertheless, a few issues that need to be considered are next discussed. Few controlled clinical trials on therapies other than antivenoms have been carried out in snakebite envenomings, although recent preclinical developments with repurposed synthetic inhibitors have paved the way for this challenging task, and clinical trials are being planned (Matthew Lewin and Nicholas Casewell, personal communication). Such trials should harness previous experiences with antivenoms, although the use of inhibitors includes some aspects that differ from antivenom studies and may require novel approaches for their design and implementation. For example, it must be decided whether phase I trials should be done or whether previous phase I trials would be acceptable. This is particularly relevant relating to: (i) dose optimization for acute snakebite indication, given that many repurposed drugs will have previously undergone clinical development for chronic disease indications, and (ii) the target population (i.e., predominately people in tropical/sub-tropical low/middle income countries), which may present differences from those who participated in prior phase I trials. Ultimately, all the information from previous trials of repurposed inhibitors should be harnessed to facilitate these new studies. 
A relevant issue is the supply of enough synthetic inhibitors manufactured following GMPs. Several aspects on the use of inhibitors in humans should be carefully considered, such as dose, route of administration, time of administration, types of settings where the studies will be carried out (i.e., hospitals or primary health care facilities), consideration on limitations in low income rural settings to carry out these studies, how the administration of inhibitors will be combined with the use of antivenoms, and the follow-up of possible inhibitor side effects or unexpected interactions with antivenoms and other drugs, among other issues. Likewise, the selection of biomarkers and clinical outcomes to assess the efficacy of these new drugs demands careful consideration, yet remains particularly challenging.

In the long term, it is anticipated that snakebite envenoming therapeutics will be strengthened by the combination of: (i) improvement of current antivenoms, both in terms of efficacy and safety, (ii) design of novel and more potent and safer antivenoms, animalderived or recombinant, (iii) the possible use of inhibitors of clinically relevant toxins, either under field conditions or in hospital settings, (iv) improvements in the accessibility of these therapies in rural settings where most snakebites occur, (v) strengthening of public health systems, including the training of physicians, nurses and other health personnel in the diagnosis and treatment of envenomings, (vi) implementation of follow-up programs for attending the physical and psychological sequelae in affected people, and (vii) improved prevention campaigns and activities based on the involvement of local communities. While aspirational, such a scenario will bring a drastic reduction in the burden of human suffering caused by snakebite, as proposed in the WHO strategy for the control and prevention of these envenomings.

Author Contributions: Conceptualization of the manuscript: J.M.G., T.M.A.E.-A.; writing—original draft preparation: J.M.G.; revision, additions, and editing of original draft and preparation of the final version of manuscript: J.M.G., L.-O.A., R.H.C., N.R.C., T.M.A.E.-A., T.E., A.R. All authors have read and agreed to the published version of the manuscript.

Funding: Some of the studies described in this review correspond to studies supported by Vicerrectoría de Investigación, University of Costa Rica.

Institutional Review Board Statement: Not applicable.

Informed Consent Statement: Not applicable.

Data Availability Statement: No new data were created or analyzed in this study. Data sharing is not applicable to this article.

Conflicts of Interest: The authors declare no conflict of interest. The funders had no role in the design of the study; in the collection, analyses, or interpretation of data; in the writing of the manuscript, or in the decision to publish the results.

\section{References}

1. Kasturiratne, A.; Wickremasinghe, A.R.; De Silva, N.; Gunawardena, N.K.; Pathmeswaran, A.; Premaratna, R.; Savioli, L.; Lalloo, D.G.; De Silva, H.J. The global burden of snakebite: A literature analysis and modelling based on regional estimates of envenoming and deaths. PLoS Med. 2008, 5, 1591-1604. [CrossRef] [PubMed]

2. Gutiérrez, J.M.; Calvete, J.J.; Habib, A.G.; Harrison, R.A.; Williams, D.J.; Warrell, D.A. Snakebite envenoming. Nat. Rev. Dis. Prim. 2017, 3, 17063. [CrossRef] [PubMed]

3. Republic of Costa Rica. Recommendation for the Adoption of an Additional Disease as a Neglected Tropical Disease. The Case for Snakebite Envenoming. 2017. Available online: https://www.who.int/snakebites/news/Recommendation_for_snakebite_ envenoming_for_adoption_of_additional_NTD.pdf (accessed on 15 March 2021).

4. Harrison, R.A.; Hargreaves, A.; Wagstaff, S.C.; Faragher, B.; Lalloo, D.G. Snake envenoming: A disease of poverty. PLoS Negl. Trop. Dis. 2009, 3. [CrossRef] [PubMed]

5. Chaves, L.F.; Chuang, T.W.; Sasa, M.; Gutiérrez, J.M. Snakebites are associated with poverty, weather fluctuations, and El Niño. Sci. Adv. 2015, 1. [CrossRef]

6. Hotez, P.J.; Fenwick, A.; Savioli, L.; Molyneux, D.H. Rescuing the bottom billion through control of neglected tropical diseases. Lancet 2009, 373, 1570-1575. [CrossRef] 
7. Molyneux, D.H. The London Declaration on Neglected Tropical Diseases: 5 years on. Trans. R. Soc. Trop. Med. Hyg. 2016, 110, 623-625. [CrossRef]

8. Gutiérrez, J.M.; Theakston, R.D.G.; Warrell, D.A. Confronting the neglected problem of snake bite envenoming: The need for a global partnership. PLoS Med. 2006, 3, 0727-0731. [CrossRef]

9. Gutiérrez, J.M.; Warrell, D.A.; Williams, D.J.; Jensen, S.; Brown, N.; Calvete, J.J.; Harrison, R.A. The Need for Full Integration of Snakebite Envenoming within a Global Strategy to Combat the Neglected Tropical Diseases: The Way Forward. PLoS Negl. Trop. Dis. 2013, 7. [CrossRef]

10. Williams, D.; Gutiérrez, J.M.; Harrison, R.; Warrell, D.A.; White, J.; Winkel, K.D.; Gopalakrishnakone, P. The Global Snake Bite Initiative: An antidote for snake bite. Lancet 2010, 375, 89-91. [CrossRef]

11. Williams, D.J.; Faiz, M.A.; Abela-Ridder, B.; Ainsworth, S.; Bulfone, T.C.; Nickerson, A.D.; Habib, A.G.; Junghanss, T.; Fan, H.W.; Turner, M.; et al. Strategy for a globally coordinated response to a priority neglected tropical disease: Snakebite envenoming. PLoS Negl. Trop. Dis. 2019, 13. [CrossRef]

12. World Health Assembly. Addressing the Burden of Snakebite Envenoming. 2018. Available online: https://www.who.int/ neglected_diseases/mediacentre/WHA_71.5_Eng.pdf?ua=1 (accessed on 11 March 2021).

13. World Health Organization. Snakebite Envenoming. A Strategy for Prevention and Control. 2019. Available online: https: //www.who.int/snakebites/resources/9789241515641/en/ (accessed on 15 March 2021).

14. Squaiella-Baptistão, C.C.; Sant'Anna, O.A.; Marcelino, J.R.; Tambourgi, D.V. The history of antivenoms development: Beyond Calmette and Vital Brazil. Toxicon 2018, 150, 86-95. [CrossRef]

15. World Health Organization. Guidelines for the Production, Control and Regulation of Snake Antivenom Immunoglobulins. 2017. Available online: https:/ / www.who.int/bloodproducts/snake_antivenoms/snakeantivenomguide/en/ (accessed on 2 April 2021).

16. León, G.; Vargas, M.; Segura, Á.; Herrera, M.; Villalta, M.; Sánchez, A.; Solano, G.; Gómez, A.; Sánchez, M.; Estrada, R.; et al. Current technology for the industrial manufacture of snake antivenoms. Toxicon 2018, 151, 63-73. [CrossRef]

17. León, G.; Herrera, M.; Segura, Á.; Villalta, M.; Vargas, M.; Gutiérrez, J.M. Pathogenic mechanisms underlying adverse reactions induced by intravenous administration of snake antivenoms. Toxicon 2013, 76, 63-76. [CrossRef]

18. De Silva, H.A.; Ryan, N.M.; De Silva, H.J. Adverse reactions to snake antivenom, and their prevention and treatment. Br. J. Clin. Pharmacol. 2016, 81, 446-452. [CrossRef]

19. Sharma, S.K.; Chappuis, F.; Jha, N.; Bovier, P.A.; Loutan, L.; Koirala, S. Impact of snake bites and determinants of fatal outcomes in Southeastern Nepal. Am. J. Trop. Med. Hyg. 2004, 71, 234-238. [CrossRef]

20. Habib, A.G.; Abubakar, S.B. Factors affecting snakebite mortality in north-eastern Nigeria. Int. Health 2011, 3, 50-55. [CrossRef]

21. Chippaux, J.P. Estimate of the burden of snakebites in sub-Saharan Africa: A meta-analytic approach. Toxicon 2011, 57, 586-599. [CrossRef]

22. Da Silva Souza, A.; Sachett, J.A.G.; Alcântara, J.A.; Freire, M.; Alecrim, M.d.G.C.; Lacerda, M.; de Lima Ferreira, L.C.; Fan, H.W.; de Souza Sampaio, V.; Monteiro, W.M. Snakebites as cause of deaths in the Western Brazilian Amazon: Why and who dies? Deaths from snakebites in the Amazon. Toxicon 2018, 145, 15-24. [CrossRef]

23. Gutiérrez, J.M.; León, G.; Rojas, G.; Lomonte, B.; Rucavado, A.; Chaves, F. Neutralization of local tissue damage induced by Bothrops asper (terciopelo) snake venom. Toxicon 1998, 36, 1529-1538. [CrossRef]

24. Rivel, M.; Solano, D.; Herrera, M.; Vargas, M.; Villalta, M.; Segura, Á.; Arias, A.S.; León, G.; Gutiérrez, J.M. Pathogenesis of dermonecrosis induced by venom of the spitting cobra, Naja nigricollis: An experimental study in mice. Toxicon 2016, 119, 171-179. [CrossRef]

25. Williams, S.S.; Wijesinghe, C.A.; Jayamanne, S.F.; Buckley, N.A.; Dawson, A.H.; Lalloo, D.G.; de Silva, H.J. Delayed psychological morbidity associated with snakebite envenoming. PLoS Negl. Trop. Dis. 2011, 5. [CrossRef]

26. Waiddyanatha, S.; Silva, A.; Siribaddana, S.; Isbister, G.K. Long-term effects of snake envenoming. Toxins 2019, 11, 193. [CrossRef]

27. Gutiérrez, J.M. Improving antivenom availability and accessibility: Science, technology, and beyond. Toxicon 2012, 60, 676-687. [CrossRef]

28. Gutiérrez, J.M.; Williams, D.; Fan, H.W.; Warrell, D.A. Snakebite envenoming from a global perspective: Towards an integrated approach. Toxicon 2010, 56, 1223-1235. [CrossRef]

29. Fan, H.W.; Monteiro, W.M. History and perspectives on how to ensure antivenom accessibility in the most remote areas in Brazil. Toxicon 2018, 151, 15-23. [CrossRef]

30. Cristino, J.S.; Salazar, G.M.; Machado, V.A.; Honorato, E.; Farias, A.S.; Vissoci, J.R.N.; Neto, A.V.S.; Lacerda, M.; Wen, F.H.; Monteiro, W.M.; et al. A painful journey to antivenom: The therapeutic itinerary of snakebite patients in the Brazilian Amazon (the QUALISnake study). PLoS Negl. Trop. Dis. 2021, 15. [CrossRef]

31. Casewell, N.R.; Jackson, T.N.W.; Laustsen, A.H.; Sunagar, K. Causes and Consequences of Snake Venom Variation. Trends Pharmacol. Sci. 2020, 41, 570-581. [CrossRef]

32. Petras, D.; Sanz, L.; Segura, Á.; Herrera, M.; Villalta, M.; Solano, D.; Vargas, M.; León, G.; Warrell, D.A.; Theakston, R.D.G.; et al. Snake venomics of African spitting cobras: Toxin composition and assessment of congeneric cross-reactivity of the Pan-African EchiTAb-Plus-ICP antivenom by antivenomics and neutralization approaches. J. Proteome Res. 2011, 10, 1266-1280. [CrossRef]

33. Fernández, J.; Alape-Girón, A.; Angulo, Y.; Sanz, L.; Gutiérrez, J.M.; Calvete, J.J.; Lomonte, B. Venomic and Antivenomic Analyses of the Central American Coral Snake, Micrurus nigrocinctus (Elapidae). J. Proteome Res. 2011, 10, 1816-1827. [CrossRef] 
34. Ainsworth, S.; Menzies, S.K.; Casewell, N.R.; Harrison, R.A. An analysis of preclinical efficacy testing of antivenoms for subSaharan Africa: Inadequate independent scrutiny and poor-quality reporting are barriers to improving snakebite treatment and management. PLoS Negl. Trop. Dis. 2020, 14, e0008579. [CrossRef]

35. Laustsen, A.; Engmark, M.; Milbo, C.; Johannesen, J.; Lomonte, B.; Gutiérrez, J.; Lohse, B. From Fangs to Pharmacology: The Future of Snakebite Envenoming Therapy. Curr. Pharm. Des. 2016, 22, 5270-5293. [CrossRef] [PubMed]

36. Laustsen, A.H.; Gutiérrez, J.M.; Knudsen, C.; Johansen, K.H.; Bermúdez-Méndez, E.; Cerni, F.A.; Jürgensen, J.A.; Ledsgaard, L.; Martos-Esteban, A.; Øhlenschlæger, M.; et al. Pros and cons of different therapeutic antibody formats for recombinant antivenom development. Toxicon 2018, 146, 151-175. [CrossRef] [PubMed]

37. Julve Parreño, J.M.; Huet, E.; Fernández-del-Carmen, A.; Segura, A.; Venturi, M.; Gandía, A.; Pan, W.S.; Albaladejo, I.; Forment, J.; Pla, D.; et al. A synthetic biology approach for consistent production of plant-made recombinant polyclonal antibodies against snake venom toxins. Plant Biotechnol. J. 2018, 16, 727-736. [CrossRef] [PubMed]

38. Clare, R.H.; Hall, S.R.; Patel, R.N.; Casewell, N.R. Small Molecule Drug Discovery for Neglected Tropical Snakebite. Trends Pharmacol. Sci. 2021, 42, 340-353. [CrossRef] [PubMed]

39. Fry, B.G.; Vidal, N.; van der Weerd, L.; Kochva, E.; Renjifo, C. Evolution and diversification of the Toxicofera reptile venom system. J. Proteom. 2009, 72, 127-136. [CrossRef] [PubMed]

40. Calvete, J.J. Venomics: Integrative venom proteomics and beyond. Biochem. J. 2017, 474, 611-634. [CrossRef]

41. Lomonte, B.; Calvete, J.J. Strategies in "snake venomics" aiming at an integrative view of compositional, functional, and immunological characteristics of venoms. J. Venom. Anim. Toxins Incl. Trop. Dis. 2017, 23. [CrossRef]

42. Suryamohan, K.; Krishnankutty, S.P.; Guillory, J.; Jevit, M.; Schröder, M.S.; Wu, M.; Kuriakose, B.; Mathew, O.K.; Perumal, R.C.; Koludarov, I.; et al. The Indian cobra reference genome and transcriptome enables comprehensive identification of venom toxins. Nat. Genet. 2020, 52, 106-117. [CrossRef]

43. Calvete, J.J.; Sanz, L.; Pla, D.; Lomonte, B.; Gutiérrez, J.M. Omics meets biology: Application to the design and preclinical assessment of antivenoms. Toxins 2014, 6, 3388-3405. [CrossRef]

44. Laustsen, A.H.; Lohse, B.; Lomonte, B.; Engmark, M.; Gutiérrez, J.M. Selecting key toxins for focused development of elapid snake antivenoms and inhibitors guided by a Toxicity Score. Toxicon 2015, 104, 43-45. [CrossRef]

45. Lomonte, B.; Fernández, J.; Sanz, L.; Angulo, Y.; Sasa, M.; Gutiérrez, J.M.; Calvete, J.J. Venomous snakes of Costa Rica: Biological and medical implications of their venom proteomic profiles analyzed through the strategy of snake venomics. J. Proteom. 2014, 105, 323-339. [CrossRef]

46. Tasoulis, T.; Isbister, G.K. A review and database of snake venom proteomes. Toxins 2017, 9, 290. [CrossRef]

47. Junqueira-de-Azevedo, I.L.M.; Campos, P.F.; Ching, A.T.C.; Mackessy, S.P. Colubrid Venom Composition: An-Omics Perspective. Toxins 2016, 8, 171. [CrossRef]

48. Fox, J.W.; Serrano, S.M.T. Structural considerations of the snake venom metalloproteinases, key members of the M12 reprolysin family of metalloproteinases. Toxicon 2005, 45, 969-985. [CrossRef]

49. Fox, J.W.; Serrano, S.M.T. Insights into and speculations about snake venom metalloproteinase (SVMP) synthesis, folding and disulfide bond formation and their contribution to venom complexity. FEBS J. 2008, 275, 3016-3030. [CrossRef]

50. Zelanis, A.; Oliveira, A.K.; Prudova, A.; Huesgen, P.F.; Tashima, A.K.; Kizhakkedathu, J.; Overall, C.M.; Serrano, S.M.T. Deep Profiling of the Cleavage Specificity and Human Substrates of Snake Venom Metalloprotease HF3 by Proteomic Identification of Cleavage Site Specificity (PICS) Using Proteome Derived Peptide Libraries and Terminal Amine Isotopic Labeling of Substrates (TAILS) N-Terminomics. J. Proteome Res. 2019, 18, 3419-3428. [CrossRef]

51. Kalogeropoulos, K.; Treschow, A.F.; Auf Dem Keller, U.; Escalante, T.; Rucavado, A.; Gutiérrez, J.M.; Laustsen, A.H.; Workman, C.T. Protease activity profiling of snake venoms using high-throughput peptide screening. Toxins 2019, 11, 170. [CrossRef]

52. Moura-da-Silva, A.; Serrano, S.M.T.; Fox, J.W.; Gutiérrez, J.M. Snake venom metalloproteinases. Structure, function and effects on snake bite pathology. In Animal Toxins: State of the Art_Perspectives in Health and Biotechnology; De Lima, M.E., De Castro, A.M., Martin-Eauclaire, M.F., Rochat, H., Eds.; Editora UFMG: Belo Horizonte, Brasil, 2009; pp. 525-546.

53. Teixeira, C.D.F.P.; Fernandes, C.M.; Zuliani, J.P.; Zamuner, S.F. Inflammatory effects of snake venom metalloproteinases. Mem. Inst. Oswaldo Cruz 2005, 100, 181-184. [CrossRef]

54. Jiménez, N.; Escalante, T.; Gutiérrez, J.M.; Rucavado, A. Skin Pathology Induced by Snake Venom Metalloproteinase: Acute Damage, Revascularization, and Re-epithelization in a Mouse Ear Model. J. Investig. Dermatol. 2008, 128, 2421-2428. [CrossRef]

55. Gutiérrez, J.M.; Romero, M.; Núñez, J.; Chaves, F.; Borkow, G.; Ovadia, M. Skeletal muscle necrosis and regeneration after injection of $\mathrm{BaH} 1$, a hemorrhagic metalloproteinase isolated from the venom of the snake Bothrops asper (Terciopelo). Exp. Mol. Pathol. 1995, 62, 28-41. [CrossRef]

56. Hernández, R.; Cabalceta, C.; Saravia-Otten, P.; Chaves, A.; Gutiérrez, J.M.; Rucavado, A. Poor regenerative outcome after skeletal muscle necrosis induced by Bothrops asper venom: Alterations in microvasculature and nerves. PLoS ONE 2011, 6. [CrossRef]

57. Williams, H.F.; Mellows, B.A.; Mitchell, R.; Sfyri, P.; Layfield, H.J.; Salamah, M.; Vaiyapuri, R.; Collins-Hooper, H.; Bicknell, A.B.; Matsakas, A.; et al. Mechanisms underpinning the permanent muscle damage induced by snake venom metalloprotease. PLoS Negl. Trop. Dis. 2019, 13. [CrossRef] [PubMed]

58. Kamiguti, A.S.; Theakston, R.D.G.; Sherman, N.; Fox, J.W. Mass spectrophotometric evidence for P-III/P-IV metalloproteinases in the venom of the Boomslang (Dispholidus typus). Toxicon 2000, 38, 1613-1620. [CrossRef] 
59. Kini, R.M. Excitement ahead: Structure, function and mechanism of snake venom phospholipase A2 enzymes. Toxicon 2003, 42, 827-840. [CrossRef]

60. Scott, D.L. Phospholipase A2: Structure and catalytic properties. In Venom Phospholipase A2 Enzymes. Structure, Function and Mechanism; Kini, R.M., Ed.; Wiley: Hoboken, NJ, USA, 1997; pp. 97-128.

61. Sunagar, K.; Jackson, T.N.W.; Reeks, T.; Fry, B.G. Group I phospholipase A2 enzymes. In Venomous Reptiles E Their Toxins. Evolution, Pathophysiology \& Biodiscovery; Fry, B.G., Ed.; Oxford University Press: Oxford, UK, 2015; pp. 327-334.

62. Sunagar, K.; Tsai, I.H.; Lomonte, B.; Jackson, T.N.W.; Fry, B.G. Group II phospholipase A2 enzymes. In Venomous Reptiles \& Their Toxins. Evolution, Pathophysiology \& Biodiscovery; Fry, B.G., Ed.; Oxford University Press: Oxford, UK, 2015; pp. 335-340.

63. Kini, R.M.; Evans, H.J. A model to explain the pharmacological effects of snake venom phospholipases A2. Toxicon 1989, 27, 613-635. [CrossRef]

64. Lomonte, B.; Rangel, J. Snake venom Lys49 myotoxins: From phospholipases A 2 to non-enzymatic membrane disruptors. Toxicon 2012, 60, 520-530. [CrossRef]

65. Kessler, P.; Marchot, P.; Silva, M.; Servent, D. The three-finger toxin fold: A multifunctional structural scaffold able to modulate cholinergic functions. J. Neurochem. 2017, 142, 7-18. [CrossRef]

66. Kini, R.M.; Doley, R. Structure, function and evolution of three-finger toxins: Mini proteins with multiple targets. Toxicon 2010, 56, 855-867. [CrossRef]

67. Utkin, Y.N.; Kuch, U.; Kasheverov, I.E.; Lebedev, D.S.; Cederlund, E.; Molles, B.E.; Polyak, I.; Ivanov, I.A.; Prokopev, N.A.; Ziganshin, R.H.; et al. Novel long-chain neurotoxins from Bungarus candidus distinguish the two binding sites in muscle-type nicotinic acetylcholine receptors. Biochem. J. 2019, 476, 1285-1302. [CrossRef]

68. Nirthanan, S.; Gwee, M.C.E. Three-Finger $\alpha$-Neurotoxins and the Nicotinic Acetylcholine Receptor, Forty Years On. J. Pharmacol. Sci. 2004, 94, 1-17. [CrossRef]

69. Warrell, D.A. Snake bite. Lancet 2010, 375, 77-88. [CrossRef]

70. Harvey, A.L. Fasciculins. Toxins from mamba venoms that inhibit acetylcholinesterase. In Handbook of Venoms and Toxins of Reptiles; Mackessy, S.P., Ed.; CRC Press: Boca Raton, FL, USA, 2010; pp. 317-324.

71. Banerjee, Y.; Lakshminarayanan, R.; Vivekanandan, S.; Anand, G.S.; Valiyaveettil, S.; Kini, R.M. Biophysical characterization of anticoagulant hemextin AB complex from the venom of snake Hemachatus haemachatus. Biophys. J. 2007, 93, 3963-3976. [CrossRef]

72. Harvey, A.L.; Hider, R.C.; Khader, F. Effect of phospholipase A on actions of cobra venom cardiotoxins on erythrocytes and skeletal muscle. BBA Biomembr. 1983, 728, 215-221. [CrossRef]

73. Konshina, A.G.; Dubovskii, P.; Efremov, R.G. Structure and Dynamics of Cardiotoxins. Curr. Protein Pept. Sci. 2012, 13, 570-584 [CrossRef]

74. Ownby, C.L.; Fletcher, J.E.; Colberg, T.R. Cardiotoxin 1 from cobra (Naja naja atra) venom causes necrosis of skeletal muscle in vivo. Toxicon 1993, 31, 697-709. [CrossRef]

75. WHO/Regional Office for Africa. Guidelines for the Prevention and Clinical Management of Snakebite in Africa; WHO: Brazzaville, Congo, 2010.

76. Pratanaphon, R.; Akesowan, S.; Khow, O.; Sriprapat, S.; Ratanabanangkoon, K. Production of highly potent horse antivenom against the Thai cobra (Naja kaouthia). Vaccine 1997, 15, 1523-1528. [CrossRef]

77. Ramos-Cerrillo, B.; de Roodt, A.R.; Chippaux, J.P.; Olguín, L.; Casasola, A.; Guzmán, G.; Paniagua-Solís, J.; Alagón, A.; Stock, R.P. Characterization of a new polyvalent antivenom (Antivipmyn ${ }^{\circledR}$ Africa) against African vipers and elapids. Toxicon 2008, 52, 881-888. [CrossRef]

78. Tan, N.H.; Wong, K.Y.; Tan, C.H. Venomics of Naja sputatrix, the Javan spitting cobra: A short neurotoxin-driven venom needing improved antivenom neutralization. J. Proteom. 2017, 157, 18-32. [CrossRef]

79. Serrano, S.M.T.; Maroun, R.C. Snake venom serine proteinases: Sequence homology vs. substrate specificity, a paradox to be solved. Toxicon 2005, 45, 1115-1132. [CrossRef]

80. Vaiyapuri, S.; Thiyagarajan, N.; Hutchinson, E.G.; Gibbins, J.M. Sequence and phylogenetic analysis of viper venom serine proteases. Bioinformation 2012, 8, 763-772. [CrossRef]

81. Philips, D.J.; Swenson, S.D.; Markland, F.S. Thrombin-like snake venom serine proteinases. In Handbook of Venoms and Toxins of Reptiles; Mackessy, S.P., Ed.; CRC Press: Boca Raton, FL, USA, 2010; pp. 139-154.

82. Ullah, A.; Masood, R.; Ali, I.; Ullah, K.; Ali, H.; Akbar, H.; Betzel, C. Thrombin-like enzymes from snake venom: Structural characterization and mechanism of action. Int. J. Biol. Macromol. 2018, 114, 788-811. [CrossRef] [PubMed]

83. Debono, J.; Bos, M.H.A.; Nouwens, A.; Ge, L.; Frank, N.; Kwok, H.F.; Fry, B.G. Habu coagulotoxicity: Clinical implications of the functional diversification of Protobothrops snake venoms upon blood clotting factors. Toxicol. Vitr. 2019, 55, 62-74. [CrossRef] [PubMed]

84. White, J. Snake venoms and coagulopathy. Toxicon 2005, 45, 951-967. [CrossRef] [PubMed]

85. Kini, R.M. The intriguing world of prothrombin activators from snake venom. Toxicon 2005, 45, 1133-1145. [CrossRef]

86. Johnston, C.I.; Ryan, N.M.; Page, C.B.; Buckley, N.A.; Brown, S.G.A.; O'Leary, M.A.; Isbister, G.K. The Australian snakebite project, 2005-2015 (ASP-20). Med. J. Aust. 2017, 207, 119-125. [CrossRef]

87. Harvey, A.L.; Robertson, B. Dendrotoxins: Structure-Activity Relationships and Effects on Potassium Ion Channels. Curr. Med. Chem. 2012, 11, 3065-3072. [CrossRef] 
88. Warrell, D.A. Clinical toxicology of snakebite in Africa and the Middle East/Arabian peninsula. In Handbook of Clinical Toxicology of Animal Venoms and Poisons; CRC Press: Boca Raton, FL, USA, 1995; pp. 433-492.

89. Bdolah, A. Sarafotoxins, the snake venom homologs of the endothelins. In Handbook of Venoms and Toxins of Reptiles; Mackessy, S.P., Ed.; CRC Press: Boca Raton, FL, USA, 2010; pp. 303-315.

90. Rucavado, A.; Escalante, T.; Camacho, E.; Gutiérrez, J.M.; Fox, J.W. Systemic vascular leakage induced in mice by Russell's viper venom from Pakistan. Sci. Rep. 2018, 8, 16088. [CrossRef]

91. Kendre, P.P.; Jose, M.P.; Varghese, A.M.; Menon, J.C.; Joseph, J.K. Capillary leak syndrome in Daboia russelii bite-A complication associated with poor outcome. Trans. R. Soc. Trop. Med. Hyg. 2018, 112, 88-93. [CrossRef]

92. Mebs, D.; Ownby, C.L. Myotoxic components of snake venoms: Their biochemical and biological activities. Pharmacol. Ther. 1990, 48, 223-236. [CrossRef]

93. Ullah, A. Structure-Function Studies and Mechanism of Action of Snake Venom L-Amino Acid Oxidases. Front. Pharmacol. 2020, 11. [CrossRef]

94. Morita, T. Structures and functions of snake venom CLPs (C-type lectin-like proteins) with anticoagulant-, procoagulant-, and platelet-modulating activities. Toxicon 2005, 45, 1099-1114. [CrossRef]

95. Clemetson, K.; Lu, Q.; Clemetson, J. Snake Venom Proteins Affecting Platelets and Their Applications to Anti-Thrombotic Research. Curr. Pharm. Des. 2007, 13, 2887-2892. [CrossRef]

96. Matsui, T.; Hamako, J. Structure and function of snake venom toxins interacting with human von Willebrand factor. Toxicon 2005, 45, 1075-1087. [CrossRef]

97. Rucavado, A.; Soto, M.; Kamiguti, A.S.; Theakston, R.D.G.; Fox, J.W.; Escalante, T.; Gutiérrez, J.M. Characterization of aspercetin, a platelet aggregating component from the venom of the snake Bothrops asper which induces thrombocytopenia and potentiates metalloproteinase-induced hemorrhage. Thromb. Haemost. 2001, 85, 710-715. [CrossRef]

98. Rucavado, A.; Escalante, T.; Arni, R. Thrombocytopenia and platelet hypoaggregation induced by Bothrops asper snake venom hemorrhage. Thromb. Haemost. 2005, 91, 123-131. [CrossRef]

99. Santoro, M.L.; Sano-Martins, I.S.; Fan, H.W.; Cardoso, J.L.C.; Theakston, R.D.G.; Warrell, D.A. Haematological evaluation of patients bitten by the jararaca, Bothrops jararaca, in Brazil. Toxicon 2008, 51, 1440-1448. [CrossRef]

100. Oliveira, S.S.; Alves, E.C.; Santos, A.S.; Pereira, J.P.T.; Sarraff, L.K.S.; Nascimento, E.F.; De-Brito-sousa, J.D.; Sampaio, V.S.; Lacerda, M.V.G.; Sachett, J.A.G.; et al. Factors associated with systemic bleeding in Bothrops envenomation in a tertiary hospital in the Brazilian Amazon. Toxins 2019, 11, 22. [CrossRef]

101. Calvete, J.J.; Marcinkiewicz, C.; Monleón, D.; Esteve, V.; Celda, B.; Juárez, P.; Sanz, L. Snake venom disintegrins: Evolution of structure and function. Toxicon 2005, 45, 1063-1074. [CrossRef]

102. Tadokoro, T.; Modahl, C.M.; Maenaka, K.; Aoki-Shioi, N. Cysteine-rich secretory proteins (CRISPs) from venomous snakes: An overview of the functional diversity in a large and underappreciated superfamily. Toxins 2020, 12, 175. [CrossRef]

103. Hayashi, M.A.F.; Camargo, A.C.M. The Bradykinin-potentiating peptides from venom gland and brain of Bothrops jararaca contain highly site specific inhibitors of the somatic angiotensin-converting enzyme. Toxicon 2005, 45, 1163-1170. [CrossRef]

104. Pla, D.; Sanz, L.; Molina-Sánchez, P.; Zorita, V.; Madrigal, M.; Flores-Díaz, M.; Alape-Girón, A.; Núñez, V.; Andrés, V.; Gutiérrez, J.M.; et al. Snake venomics of Lachesis muta rhombeata and genus-wide antivenomics assessment of the paraspecific immunoreactivity of two antivenoms evidence the high compositional and immunological conservation across Lachesis. J. Proteom. 2013, 89, 112-123. [CrossRef] [PubMed]

105. Teixeira, C.; Moreira, V.; Gutiérrez, J.M. Venoms. In Inflammation: From Molecular and Cellular Mechanisms to the Clinic; Cavaillon, J.M., Singer, M.E., Eds.; Wiley: Hoboken, NJ, USA, 2018; pp. 99-128.

106. Bickler, P.E. Amplification of Snake Venom Toxicity by Endogenous Signaling Pathways. Toxins 2020, 12, 68. [CrossRef] [PubMed]

107. Zornetta, I.; Caccin, P.; Fernandez, J.; Lomonte, B.; Gutierrez, J.M.; Montecucco, C. Envenomations by Bothrops and Crotalus snakes induce the release of mitochondrial alarmins. PLoS Negl. Trop. Dis. 2012, 6. [CrossRef] [PubMed]

108. Rucavado, A.; Nicolau, C.A.; Escalante, T.; Kim, J.; Herrera, C.; Gutiérrez, J.M.; Fox, J.W. Viperid envenomation wound exudate contributes to increased vascular permeability via a DAMPs/TLR-4 mediated pathway. Toxins 2016, 8, 349. [CrossRef]

109. Moreira, V.; Teixeira, C.; Borges da Silva, H.; D'Império Lima, M.R.; Dos-Santos, M.C. The role of TLR2 in the acute inflammatory response induced by Bothrops atrox snake venom. Toxicon 2016, 118, 121-128. [CrossRef]

110. Zoccal, K.F.; Bitencourt, C.S.; Paula-Silva, F.W.G.; Sorgi, C.A.; Bordon, K.C.F.; Arantes, E.C.; Faccioli, L.H. TLR2, TLR4 and CD14 recognize venom-associated molecular patterns from Tityus serrulatus to induce macrophage-derived inflammatory mediators. PLoS ONE 2014, 9, e88174. [CrossRef]

111. Sharma, R.D.; Katkar, G.D.; Sundaram, M.S.; Paul, M.; NaveenKumar, S.K.; Swethakumar, B.; Hemshekhar, M.; Girish, K.S.; Kemparaju, K. Oxidative stress-induced methemoglobinemia is the silent killer during snakebite: A novel and strategic neutralization by melatonin. J. Pineal Res. 2015, 59, 240-254. [CrossRef]

112. Gold, B.S. Neostigmine for the treatment of neurotoxicity following envenomation by the Asiatic cobra. Ann. Emerg. Med. 1996, 28, 87-89. [CrossRef]

113. Lewin, M.R.; Samuel, S.P.; Wexler, D.S.; Bickler, P.; Vaiyapuri, S.; Mensh, B.D. Early treatment with intranasal neostigmine reduces mortality in a mouse model of Naja naja (Indian cobra) envenomation. J. Trop. Med. 2014, 2014. [CrossRef] 
114. Faiz, M.A.; Ahsan, M.F.; Ghose, A.; Rahman, M.R.; Amin, R.; Hossain, M.; Tareq, M.N.U.; Jalil, M.A.; Kuch, U.; Theakston, R.D.G.; et al. Bites by the Monocled Cobra, Naja kaouthia, in Chittagong Division, Bangladesh: Epidemiology, clinical features of envenoming and management of 70 identified cases. Am. J. Trop. Med. Hyg. 2017, 96, 876-884. [CrossRef]

115. Stazi, M.; D'este, G.; Mattarei, A.; Negro, S.; Lista, F.; Rigoni, M.; Megighian, A.; Montecucco, C. An agonist of the cxcr4 receptor accelerates the recovery from the peripheral neuroparalysis induced by taipan snake envenomation. PLoS Negl. Trop. Dis. 2020, 14, e0008547. [CrossRef]

116. Gutiérrez, J.M.; Escalante, T.; Hernández, R.; Gastaldello, S.; Saravia-Otten, P.; Rucavado, A. Why is skeletal muscle regeneration impaired after myonecrosis induced by viperid snake venoms? Toxins 2018, 10, 182. [CrossRef]

117. Sanchez-Castro, E.E.; Pajuelo-Reyes, C.; Tejedo, R.; Soria-Juan, B.; Tapia-Limonchi, R.; Andreu, E.; Hitos, A.B.; Martin, F.; Cahuana, G.M.; Guerra-Duarte, C.; et al. Mesenchymal Stromal Cell-Based Therapies as Promising Treatments for Muscle Regeneration after Snakebite Envenoming. Front. Immunol. 2021, 11. [CrossRef]

118. Knudsen, C.; Ledsgaard, L.; Dehli, R.I.; Ahmadi, S.; Sørensen, C.V.; Laustsen, A.H. Engineering and design considerations for next-generation snakebite antivenoms. Toxicon 2019, 167, 67-75. [CrossRef]

119. Knudsen, C.; Casewell, N.R.; Lomonte, B.; Gutiérrez, J.M.; Vaiyapuri, S.; Laustsen, A.H. Novel Snakebite Therapeutics Must Be Tested in Appropriate Rescue Models to Robustly Assess Their Preclinical Efficacy. Toxins 2020, 12, 528. [CrossRef]

120. Mors, W.B.; Célia Do Nascimento, M.; Ruppelt Pereira, B.M.; Alvares Pereira, N. Plant natural products active against snake bite-The molecular approach. Phytochemistry 2000, 55, 627-642. [CrossRef]

121. Soares, A.M.; Ticli, F.K.; Marcussi, S.; Lourenco, M.V.; Januario, A.H.; Sampaio, S.V.; Giglio, J.R.; Lomonte, B.; Pereira, P.S. Medicinal Plants with Inhibitory Properties Against Snake Venoms. Curr. Med. Chem. 2005, 12, 2625-2641. [CrossRef]

122. Carvalho, B.M.A.; Santos, J.D.L.; Xavier, B.M.; Almeida, J.R.; Resende, L.M.; Martins, W.; Marcussi, S.; Marangoni, S.; Stábeli, R.G.; Calderon, L.A.; et al. Snake venom PLA2s inhibitors isolated from Brazilian plants: Synthetic and natural molecules. BioMed Res. Int. 2013, 2013. [CrossRef]

123. Shabbir, A.; Shahzad, M.; Masci, P.; Gobe, G.C. Protective activity of medicinal plants and their isolated compounds against the toxic effects from the venom of Naja (cobra) species. J. Ethnopharmacol. 2014, 157, 222-227. [CrossRef]

124. Félix-Silva, J.; Silva-Junior, A.A.; Zucolotto, S.M.; Fernandes-Pedrosa, M.D.F. Medicinal Plants for the Treatment of Local Tissue Damage Induced by Snake Venoms: An Overview from Traditional Use to Pharmacological Evidence. Evid. Based Complementary Altern. Med. 2017, 2017. [CrossRef]

125. De Moura, V.M.; de Souza, L.Y.A.; da Costa Guimarães, N.; dos Santos, I.G.C.; de Almeida, P.D.O.; de Oliveira, R.B.; Mourão, R.H.V.; Dos-Santos, M.C. The potential of aqueous extracts of Bellucia dichotoma Cogn. (Melastomataceae) to inhibit the biological activities of Bothrops atrox venom: A comparison of specimens collected in the states of Pará and Amazonas, Brazil. J. Ethnopharmacol. 2017, 196, 168-177. [CrossRef]

126. Núñez, V.; Otero, R.; Barona, J.; Saldarriaga, M.; Osorio, R.G.; Fonnegra, R.; Jiménez, S.L.; Díaz, A.; Quintana, J.C. Neutralization of the edema-forming, defibrinating and coagulant effects of Bothrops asper venom by extracts of plants used by healers in Columbia. Braz. J. Med. Biol. Res. 2004, 37, 969-977. [CrossRef]

127. Núñez, V.; Castro, V.; Murillo, R.; Ponce-Soto, L.A.; Merfort, I.; Lomonte, B. Inhibitory effects of Piper umbellatum and Piper peltatum extracts towards myotoxic phospholipases A2 from Bothrops snake venoms: Isolation of 4-nerolidylcatechol as active principle. Phytochemistry 2005, 66, 1017-1025. [CrossRef]

128. De Moura, V.M.; Freitas De Sousa, L.A.; Cristina Dos-Santos, M.; Almeida Raposo, J.D.; Evangelista Lima, A.; De Oliveira, R.B.; Da Silva, M.N.; Veras Mourão, R.H. Plants used to treat snakebites in Santarém, western Pará, Brazil: An assessment of their effectiveness in inhibiting hemorrhagic activity induced by Bothrops jararaca venom. J. Ethnopharmacol. 2015, 161, $224-232$. [CrossRef]

129. Patiño, A.C.; Quintana, J.C.; Gutiérrez, J.M.; Rucavado, A.; Benjumea, D.M.; Pereañez, J.A. Extracts of Renealmia alpinia (rottb.) MAAS protect against lethality and systemic hemorrhage induced by Bothrops asper venom: Insights from a model with extract administration before venom injection. Toxins 2015, 7, 1532-1543. [CrossRef]

130. Otero, R.; Núñez, V.; Jiménez, S.L.; Fonnegra, R.; Osorio, R.G.; García, M.E.; Díaz, A. Snakebites and ethnobotany in the northwest region of Colombia. Part II: Neutralization of lethal and enzymatic effects of Bothrops atrox venom. J. Ethnopharmacol. 2000, 71, 505-511. [CrossRef]

131. Singh, A.K.; Raghubanshi, A.S.; Singh, J.S. Medical ethnobotany of the tribals of Sonaghati of Sonbhadra district, Uttar Pradesh, India. J. Ethnopharmacol. 2002, 81, 31-41. [CrossRef]

132. Chen, Q.; Wang, W.; Li, Q.; Bai, Y.; Zou, X.; Wu, Y. Effect of externally applied Jidesheng anti-venom on skin and soft-tissue necrosis after Chinese cobra bite: A retrospective study. J. Tradit. Chin. Med. 2014, 34, 150-154. [CrossRef]

133. Chandra, V.; Jasti, J.; Kaur, P.; Srinivasan, A.; Betzel, C.; Singh, T.P. Structural basis of phospholipase A2 inhibition for the synthesis of prostaglandins by the plant alkaloid aristolochic acid from a $1.7 \AA$ crystal structure. Biochemistry 2002, 41, 10914-10919. [CrossRef] [PubMed]

134. Dos Santos, J.I.; Cardoso, F.F.; Soares, A.M.; dal Pai Silva, M.; Gallacci, M.; Fontes, M.R.M. Structural and functional studies of a bothropic myotoxin complexed to rosmarinic acid: New insights into Lys49-PLA 2 inhibition. PLoS ONE 2011, 6. [CrossRef]

135. Shimabuku, P.S.; Fernandes, C.A.H.; Magro, A.J.; Costa, T.R.; Soares, A.M.; Fontes, M.R.M. Crystallization and preliminary X-ray diffraction analysis of a Lys49-phospholipase A2 complexed with caffeic acid, a molecule with inhibitory properties against snake venoms. Acta Crystallogr. Sect. F Struct. Biol. Cryst. Commun. 2011, 67, 249-252. [CrossRef] 
136. Pereañez, J.A.; Patiño, A.C.; Núñez, V.; Osorio, E. The biflavonoid morelloflavone inhibits the enzymatic and biological activities of a snake venom phospholipase A2. Chem. Biol. Interact. 2014, 220, 94-101. [CrossRef]

137. Preciado, L.M.; Comer, J.; Núñez, V.; Rey-Súarez, P.; Pereañez, J.A. Inhibition of a snake venom metalloproteinase by the flavonoid myricetin. Molecules 2018, 23, 2662. [CrossRef]

138. Kumar, M.S.; Amjesh, R.; Bhaskaran, S.; Delphin, R.D.; Nair, A.S.; Sudhakaran, P.R. Molecular docking and dynamic studies of crepiside E beta glucopyranoside as an inhibitor of snake venom PLA2. J. Mol. Model. 2019, 25. [CrossRef]

139. Neves-Ferreira, A.G.C.; Valente, R.H.; Perales, J.; Domont, G.B. Natural inhibitors. Innate immunity to snake venoms. In Handbook of Venoms and Toxins of Reptiles; Mackessy, S.P., Ed.; CRC Press: Boca Raton, FL, USA, 2010; pp. 259-284.

140. Bastos, V.A.; Gomes-Neto, F.; Perales, J.; Neves-Ferreira, A.G.C.; Valente, R.H. Natural inhibitors of snake venom metalloendopeptidases: History and current challenges. Toxins 2016, 8, 250. [CrossRef]

141. Lizano, S.; Domont, G.; Perales, J. Natural phospholipase A2 myotoxin inhibitor proteins from snakes, mammals and plants. Toxicon 2003, 42, 963-977. [CrossRef]

142. Rocha, S.L.G.; Lomonte, B.; Neves-Ferreira, A.G.C.; Trugilho, M.R.O.; Junqueira-de-Azevedo, I.D.L.M.; Ho, P.L.; Domont, G.B.; Gutiérrez, J.M.; Perales, J. Functional analysis of DM64, an antimyotoxic protein with immunoglobulin-like structure from Didelphis marsupialis serum. Eur. J. Biochem. 2002, 269, 6052-6062. [CrossRef]

143. Metz, M.; Piliponsky, A.M.; Chan, C.C.; Lammel, V.; Åbrink, M.; Pejler, G.; Tsai, M.; Galli, S.J. Mast cells can enhance resistance to snake and honeybee venoms. Science 2006, 313, 526-530. [CrossRef]

144. Galli, S.J.; Metz, M.; Starkl, P.; Marichal, T.; Tsai, M. Mast cells and IgE in defense against lethality of venoms: Possible "benefit" of allergy. Allergo J. Int. 2020, 29, 46-62. [CrossRef]

145. Anderson, E.; Stavenhagen, K.; Kolarich, D.; Sommerhoff, C.P.; Maurer, M.; Metz, M. Human mast cell tryptase is a potential treatment for snakebite envenoming across multiple snake species. Front. Immunol. 2018, 9. [CrossRef]

146. Melo, P.A.; Homsi-Brandeburgo, M.I.; Giglio, J.R.; Suarez-Kurtz, G. Antagonism of the myotoxic effects of Bothrops jararacussu venom and bothropstoxin by polyanions. Toxicon 1993, 31, 285-291. [CrossRef]

147. Lomonte, B.; Tarkowski, A.; Bagge, U.; Hanson, L.Å. Neutralization of the cytolytic and myotoxic activities of phospholipases A2 from Bothrops asper snake venom by glycosaminoglycans of the heparin/heparan sulfate family. Biochem. Pharmacol. 1994, 47, 1509-1518. [CrossRef]

148. Itoh, Y.; Nagase, H. Matrix metalloproteinases in cancer. Essays Biochem. 2002, 38, 21-36. [CrossRef]

149. Nissinen, L.; Kähäri, V.-M. Matrix metalloproteinases in inflammation. Biochim. Biophys. Acta Gen. Subj. 2014, 1840, $2571-2580$. [CrossRef]

150. Gharib, S.A.; Manicone, A.M.; Parks, W.C. Matrix metalloproteinases in emphysema. Matrix Biol. 2018, 73, 34-51. [CrossRef]

151. Conrad, C.; Benzel, J.; Dorzweiler, K.; Cook, L.; Schlomann, U.; Zarbock, A.; Slater, E.P.; Nimsky, C.; Bartsch, J.W. ADAM8 in invasive cancers: Links to tumor progression, metastasis, and chemoresistance. Clin. Sci. 2019, 133, 83-99. [CrossRef]

152. Fischer, T.; Senn, N.; Riedl, R. Design and Structural Evolution of Matrix Metalloproteinase Inhibitors. Chem. A Eur. J. 2019, 25, 7960-7980. [CrossRef]

153. Mannello, F.; Tonti, G.; Papa, S. Matrix Metalloproteinase Inhibitors as Anticancer Therapeutics. Curr. Cancer Drug Targets 2005, 5, 285-298. [CrossRef] [PubMed]

154. Zhong, Y.; Lu, Y.T.; Sun, Y.; Shi, Z.H.; Li, N.G.; Tang, Y.P.; Duan, J.A. Recent opportunities in matrix metalloproteinase inhibitor drug design for cancer. Expert Opin. Drug Discov. 2018, 13, 75-87. [CrossRef] [PubMed]

155. Dufour, A.; Sampson, N.S.; Li, J.; Kuscu, C.; Rizzo, R.C.; DeLeon, J.L.; Zhi, J.; Jaber, N.; Liu, E.; Zucker, S.; et al. Small-molecule anticancer compounds selectively target the hemopexin domain of matrix metalloproteinase-9. Cancer Res. 2011, 71, 4977-4988. [CrossRef] [PubMed]

156. Escalante, T.; Franceschi, A.; Rucavado, A.; Gutiérrez, J.M. Effectiveness of batimastat, a synthetic inhibitor of matrix metalloproteinases, in neutralizing local tissue damage induced by BaP1, a hemorrhagic metalloproteinase from the venom of the snake Bothrops asper. Biochem. Pharmacol. 2000, 60, 269-274. [CrossRef]

157. Rucavado, A.; Escalante, T.; Franceschi, A.; Chaves, F.; León, G.; Cury, Y.; Ovadia, M.; Gutiérrez, J.M. Inhibition of local hemorrhage and dermonecrosis induced by Bothrops asper snake venom: Effectiveness of early in situ administration of the peptidomimetic metalloproteinase inhibitor batimastat and the chelating agent CaNa2EDTA. Am. J. Trop. Med. Hyg. 2000, 63, 313-319. [CrossRef]

158. Arias, A.S.; Rucavado, A.; Gutiérrez, J.M. Peptidomimetic hydroxamate metalloproteinase inhibitors abrogate local and systemic toxicity induced by Echis ocellatus (saw-scaled) snake venom. Toxicon 2017, 132, 40-49. [CrossRef]

159. Albulescu, L.O.; Xie, C.; Ainsworth, S.; Alsolaiss, J.; Crittenden, E.; Dawson, C.A.; Softley, R.; Bartlett, K.E.; Harrison, R.A.; Kool, J.; et al. A therapeutic combination of two small molecule toxin inhibitors provides broad preclinical efficacy against viper snakebite. Nat. Commun. 2020, 11. [CrossRef]

160. Borkow, G.; Gutierrez, J.M.; Ovadia, M. Inhibition of toxic activities of Bothrops asper venom and other crotalid snake venoms by a novel neutralizing mixture. Toxicol. Appl. Pharmacol. 1997, 147, 442-447. [CrossRef]

161. Albulescu, L.O.; Hale, M.S.; Ainsworth, S.; Alsolaiss, J.; Crittenden, E.; Calvete, J.J.; Evans, C.; Wilkinson, M.C.; Harrison, R.A.; Kool, J.; et al. Preclinical validation of a repurposed metal chelator as an early-intervention therapeutic for hemotoxic snakebite. Sci. Transl. Med. 2020, 12. [CrossRef] 
162. Rudresha, G.V.; Urs, A.P.; Manjuprasanna, V.N.; Milan Gowda, M.D.; Jayachandra, K.; Rajaiah, R.; Vishwanath, B.S. Echis carinatus snake venom metalloprotease-induced toxicities in mice: Therapeutic intervention by a repurposed drug, tetraethyl thiuram disulfide (Disulfiram). PLoS Negl. Trop. Dis. 2021, 15, e0008596. [CrossRef]

163. Rucavado, A.; Henríquez, M.; García, J.; Gutiérrez, J.M. Assessment of metalloproteinase inhibitors clodronate and doxycycline in the neutralization of hemorrhage and coagulopathy induced by Bothrops asper snake venom. Toxicon 2008, 52, 754-759. [CrossRef]

164. Nakamoto, M.; Escalante, T.; Gutiérrez, J.M.; Shea, K.J. A Biomimetic of Endogenous Tissue Inhibitors of Metalloproteinases: Inhibition Mechanism and Contribution of Composition, Polymer Size and Shape to the Inhibitory Effect. Nano Lett. 2021, in press. [CrossRef]

165. Dennis, E.A.; Cao, J.; Hsu, Y.H.; Magrioti, V.; Kokotos, G. Phospholipase A2 enzymes: Physical structure, biological function, disease implication, chemical inhibition, and therapeutic intervention. Chem. Rev. 2011, 111, 6130-6185. [CrossRef]

166. Magrioti, V.; Kokotos, G. Phospholipase A2 inhibitors for the treatment of inflammatory diseases: A patent review (2010-present). Expert Opin. Ther. Pat. 2013, 23, 333-344. [CrossRef] [PubMed]

167. Murakami, M.; Nakatani, Y.; Atsumi, G.I.; Inoue, K.; Kudo, I. Regulatory functions of phospholipase A2. Crit. Rev. Immunol. 2017, 37, 121-180. [CrossRef] [PubMed]

168. Serruys, P.W.; Garcia-Garcia, H.M. Phospholipase A2 inhibitors. Curr. Opin. Lipidol. 2009, 20, 327-332. [CrossRef]

169. Adis, R. Varespladib. Am. J. Cardiovasc. Drugs 2011, 11, 137-143. [CrossRef]

170. Nicholls, S.J.; Kastelein, J.J.P.; Schwartz, G.G.; Bash, D.; Rosenson, R.S.; Cavender, M.A.; Brennan, D.M.; Koenig, W.; Jukema, J.W.; Nambi, V.; et al. Varespladib and cardiovascular events in patients with an acute coronary syndrome: The VISTA-16 randomized clinical trial. JAMA J. Am. Med. Assoc. 2014, 311, 252-262. [CrossRef]

171. Rosenson, R.S.; Hislop, C.; Elliott, M.; Stasiv, Y.; Goulder, M.; Waters, D. Effects of varespladib methyl on biomarkers and major cardiovascular events in acute coronary syndrome patients. J. Am. Coll. Cardiol. 2010, 56, 1079-1088. [CrossRef]

172. Lewin, M.; Samuel, S.; Merkel, J.; Bickler, P. Varespladib (LY315920) appears to be a potent, broad-spectrum, inhibitor of snake venom phospholipase A2 and a possible pre-referral treatment for envenomation. Toxins 2016, 8, 248. [CrossRef]

173. Lewin, M.R.; Gutiérrez, J.M.; Samuel, S.P.; Herrera, M.; Bryan-Quirós, W.; Lomonte, B.; Bickler, P.E.; Bulfone, T.C.; Williams, D.J. Delayed oral LY333013 rescues mice from highly neurotoxic, lethal doses of papuan taipan (Oxyuranus scutellatus) venom. Toxins 2018, 10, 380. [CrossRef]

174. Lewin, M.R.; Gilliam, L.L.; Gilliam, J.; Samuel, S.P.; Bulfone, T.C.; Bickler, P.E.; Gutiérrez, J.M. Delayed LY333013 (oral) and LY315920 (intravenous) reverse severe neurotoxicity and rescue juvenile pigs from lethal doses of Micrurus fulvius (eastern coral snake) venom. Toxins 2018, 10, 479. [CrossRef]

175. Gutiérrez, J.M.; Lewin, M.R.; Williams, D.J.; Lomonte, B. Varespladib (LY315920) and methyl varespladib (LY333013) abrogate or delay lethality induced by presynaptically acting neurotoxic snake venoms. Toxins 2020, 12, 131. [CrossRef]

176. Fontana Oliveira, I.C.; Gutiérrez, J.M.; Lewin, M.R.; Oshima-Franco, Y. Varespladib (LY315920) inhibits neuromuscular blockade induced by Oxyuranus scutellatus venom in a nerve-muscle preparation. Toxicon 2020, 187, 101-104. [CrossRef]

177. Bryan-Quirós, W.; Fernández, J.; Gutiérrez, J.M.; Lewin, M.R.; Lomonte, B. Neutralizing properties of LY315920 toward snake venom group I and II myotoxic phospholipases A2. Toxicon 2019, 157, 1-7. [CrossRef]

178. Xiao, H.; Li, H.; Zhang, D.; Li, Y.; Sun, S.; Huang, C. Inactivation of venom PLA2 alleviates myonecrosis and facilitates muscle regeneration in envenomed mice: A time course observation. Molecules 2018, 23, 1911. [CrossRef]

179. Kini, R.M. Structure-function relationships and mechanism of anticoagulant phospholipase A2 enzymes from snake venoms. Toxicon 2005, 45, 1147-1161. [CrossRef]

180. Xie, C.; Albulescu, L.O.; Still, K.B.M.; Slagboom, J.; Zhao, Y.; Jiang, Z.; Somsen, G.W.; Vonk, F.J.; Casewell, N.R.; Kool, J. Varespladib inhibits the phospholipase A2 and coagulopathic activities of venom components from hemotoxic snakes. Biomedicines 2020, 8 , 165. [CrossRef]

181. Youngman, N.J.; Walker, A.; Naude, A.; Coster, K.; Sundman, E.; Fry, B.G. Varespladib (LY315920) neutralises phospholipase A2 mediated prothrombinase-inhibition induced by Bitis snake venoms. Comp. Biochem. Physiol. Part C Toxicol. Pharmacol. 2020, 236. [CrossRef]

182. Zdenek, C.N.; Youngman, N.J.; Hay, C.; Dobson, J.; Dunstan, N.; Allen, L.; Milanovic, L.; Fry, B.G. Anticoagulant activity of black snake (Elapidae: Pseudechis) venoms: Mechanisms, potency, and antivenom efficacy. Toxicol. Lett. 2020, 330, 176-184. [CrossRef]

183. Dashevsky, D.; Bénard-Valle, M.; Neri-Castro, E.; Youngman, N.J.; Zdenek, C.N.; Alagón, A.; Portes-Junior, J.A.; Frank, N.; Fry, B.G. Anticoagulant Micrurus venoms: Targets and neutralization. Toxicol. Lett. 2021, 337, 91-97. [CrossRef]

184. Lomonte, B.; Gutiérrez, J. A new muscle damaging toxin, myotoxin II, from the venom of the snake Bothrops asper (terciopelo). Toxicon 1989, 27, 725-733. [CrossRef]

185. Chacur, M.; Longo, I.; Picolo, G.; Gutiérrez, J.M.; Lomonte, B.; Guerra, J.L.; Teixeira, C.F.P.; Cury, Y. Hyperalgesia induced by Asp49 and Lys49 phospholipases A2 from Bothrops asper snake venom: Pharmacological mediation and molecular determinants. Toxicon 2003, 41, 667-678. [CrossRef]

186. Zuliani, J.P.; Fernandes, C.M.; Zamuner, S.R.; Gutiérrez, J.M.; Teixeira, C.F.P. Inflammatory events induced by Lys-49 and Asp-49 phospholipases A 2 isolated from Bothrops asper snake venom: Role of catalytic activity. Toxicon 2005, 45, 335-346. [CrossRef] [PubMed] 
187. Salvador, G.H.M.; Gomes, A.A.S.; Bryan-Quirós, W.; Fernández, J.; Lewin, M.R.; Gutiérrez, J.M.; Lomonte, B.; Fontes, M.R.M. Structural basis for phospholipase A2-like toxin inhibition by the synthetic compound Varespladib (LY315920). Sci. Rep. 2019, 9. [CrossRef] [PubMed]

188. Lomonte, B.; Moreno, E.; Tarkowski, A.; Hanson, L.A.; Maccarana, M. Neutralizing interaction between heparins and myotoxin II, a lysine 49 phospholipase A2 from Bothrops asper snake venom. Identification of a heparin-binding and cytolytic toxin region by the use of synthetic peptides and molecular modeling. J. Biol. Chem. 1994, 269, 29867-29873. [CrossRef]

189. De Oliveira, M.; Cavalcante, W.L.G.; Arruda, E.Z.; Melo, P.A.; Dal-Pai Silva, M.; Gallacci, M. Antagonism of myotoxic and paralyzing activities of bothropstoxin-I by suramin. Toxicon 2003, 42, 373-379. [CrossRef]

190. Murakami, M.T.; Arruda, E.Z.; Melo, P.A.; Martinez, A.B.; Calil-Eliás, S.; Tomaz, M.A.; Lomonte, B.; Gutiérrez, J.M.; Arni, R.K. Inhibition of myotoxic activity of Bothrops asper myotoxin II by the anti-trypanosomal drug suramin. J. Mol. Biol. 2005, 350, 416-426. [CrossRef]

191. Salvador, G.H.M.; Dreyer, T.R.; Gomes, A.A.S.; Cavalcante, W.L.G.; Dos Santos, J.I.; Gandin, C.A.; De Oliveira Neto, M.; Gallacci, M.; Fontes, M.R.M. Structural and functional characterization of suramin-bound MjTX-I from Bothrops moojeni suggests a particular myotoxic mechanism. Sci. Rep. 2018, 8. [CrossRef]

192. Raw, I.; Rocha, M.C.; Esteves, M.I.; Kamiguti, A.S. Isolation and characterization of a thrombin-like enzyme from the venom of Crotalus durissus terrificus. Braz. J. Med. Biol. Res. 1986, 19, 333-338.

193. Aguiar, A.S.; Alves, C.R.; Melgarejo, A.; Giovanni-De-Simone, S. Purification and partial characterization of a thrombinlike/gyroxin enzyme from bushmaster (Lachesis muta rhombeata) venom. Toxicon 1996, 34, 555-565. [CrossRef]

194. Barber, C.M.; Isbister, G.K.; Hodgson, W.C. Alpha neurotoxins. Toxicon 2013, 66, 47-58. [CrossRef]

195. Albulescu, L.O.; Kazandjian, T.; Slagboom, J.; Bruyneel, B.; Ainsworth, S.; Alsolaiss, J.; Wagstaff, S.C.; Whiteley, G.; Harrison, R.A.; Ulens, C.; et al. A decoy-receptor approach using nicotinic acetylcholine receptor mimics reveals their potential as novel therapeutics against neurotoxic snakebite. Front. Pharmacol. 2019, 10. [CrossRef]

196. Zdenek, C.N.; Harris, R.J.; Kuruppu, S.; Youngman, N.J.; Dobson, J.S.; Debono, J.; Khan, M.; Smith, I.; Yarski, M.; Harrich, D.; et al. A taxon-specific and high-throughput method for measuring ligand binding to nicotinic acetylcholine receptors. Toxins 2019, 11, 600. [CrossRef]

197. Harris, R.J.; Youngman, N.J.; Zdenek, C.N.; Huynh, T.M.; Nouwens, A.; Hodgson, W.C.; Harrich, D.; Dunstan, N.; Portes-Junior, J.A.; Fry, B.G. Assessing the binding of venoms from aquatic elapids to the nicotinic acetylcholine receptor orthosteric site of different prey models. Int. J. Mol. Sci. 2020, 21, 7377. [CrossRef]

198. El-Aziz, T.M.A.; Ravelet, C.; Molgo, J.; Fiore, E.; Pale, S.; Amar, M.; Al-Khoury, S.; Dejeu, J.; Fadl, M.; Ronjat, M.; et al. Efficient functional neutralization of lethal peptide toxins in vivo by oligonucleotides. Sci. Rep. 2017, 7. [CrossRef]

199. Taiwe, G.S.; Montnach, J.; Nicolas, S.; De Waard, S.; Fiore, E.; Peyrin, E.; El-Aziz, T.M.A.; Amar, M.; Molgó, J.; Ronjat, M.; et al. Aptamer efficacies for in vitro and in vivo modulation of $\alpha$ C-conotoxin PrXA pharmacology. Molecules 2019, 24, 229. [CrossRef]

200. Lauridsen, L.H.; Shamaileh, H.A.; Edwards, S.L.; Taran, E.; Veedu, R.N. Rapid one-step selection method for generating nucleic acid aptamers: Development of a DNA Aptamer against $\alpha$-bungarotoxin. PLoS ONE 2012, 7. [CrossRef]

201. Chen, Y.J.; Tsai, C.Y.; Hu, W.P.; Chang, L. Sen DNA aptamers against Taiwan banded krait $\alpha$-bungarotoxin recognize Taiwan cobra cardiotoxins. Toxins 2016, 8, 66. [CrossRef]

202. Lynagh, T.; Kiontke, S.; Meyhoff-Madsen, M.; Gless, B.H.; Johannesen, J.; Kattelmann, S.; Christiansen, A.; Dufva, M.; Laustsen, A.H.; Devkota, K.; et al. Peptide Inhibitors of the $\alpha$-Cobratoxin-Nicotinic Acetylcholine Receptor Interaction. J. Med. Chem. 2020, 63, 13709-13718. [CrossRef]

203. O'Brien, J.; Lee, S.H.; Onogi, S.; Shea, K.J. Engineering the Protein Corona of a Synthetic Polymer Nanoparticle for Broad-Spectrum Sequestration and Neutralization of Venomous Biomacromolecules. J. Am. Chem. Soc. 2016, 138, 16604-16607. [CrossRef]

204. O'Brien, J.; Lee, S.H.; Gutiérrez, J.M.; Shea, K.J. Engineered nanoparticles bind elapid snake venom toxins and inhibit venominduced dermonecrosis. PLoS Negl. Trop. Dis. 2018, 12. [CrossRef]

205. Kemparaju, K.; Girish, K.; Nagaraju, S. Hyaluronidases, a Neglected Class of Glycosidases from Snake Venom. In Handbook of Venoms and Toxins of Reptiles; Mackessy, S.P., Ed.; CRC Press: Boca Raton, FL, USA, 2010; pp. 237-258.

206. Yingprasertchai, S.; Bunyasrisawat, S.; Ratanabanangkoon, K. Hyaluronidase inhibitors (sodium cromoglycate and sodium aurothiomalate) reduce the local tissue damage and prolong the survival time of mice injected with Naja kaouthia and Calloselasma rhodostoma venoms. Toxicon 2003, 42, 635-646. [CrossRef]

207. Khedrinia, M.; Aryapour, H.; Mianabadi, M. Prediction of novel inhibitors for Crotalus adamanteus L-amino acid oxidase by repurposing FDA-approved drugs: A virtual screening and molecular dynamics simulation investigation. Drug Chem. Toxicol. 2019. [CrossRef]

208. Chung, H.; Dai, T.; Sharma, S.K.; Huang, Y.Y.; Carroll, J.D.; Hamblin, M.R. The nuts and bolts of low-level laser (Light) therapy. Ann. Biomed. Eng. 2012, 40, 516-533. [CrossRef]

209. Silva, L.M.G.; Zamuner, L.F.; David, A.C.; dos Santos, S.A.; de Carvalho, P.d.T.C.; Zamuner, S.R. Photobiomodulation therapy on Bothrops snake venom-induced local pathological effects: A systematic review. Toxicon 2018, 152, 23-29. [CrossRef]

210. Nadur-Andrade, N.; Dale, C.S.; Dos Santos, A.S.; Soares, A.M.; De Lima, C.J.; Zamuner, S.R. Photobiostimulation reduces edema formation induced in mice by Lys-49 phospholipases A2 isolated from Bothrops moojeni venom. Photochem. Photobiol. Sci. 2014, 13, 1561-1567. [CrossRef] 
211. Campos, G.R.S.; de Moura, K.M.B.; Barbosa, A.M.; Zamuner, L.F.; Nadur-Andrade, N.; Dale, C.S.; Gutiérrez, J.M.; Chavantes, M.C.; Zamuner, S.R. Light emitting diode (LED) therapy reduces local pathological changes induced by Bothrops asper snake venom. Toxicon 2018, 152, 95-102. [CrossRef]

212. Nadur-Andrade, N.; Zamuner, S.R.; Toniolo, E.F.; De Lima, C.J.; Cogo, J.C.; Dale, C.S. Analgesic effect of light-emitting diode (LED) therapy at wavelengths of 635 and $945 \mathrm{~nm}$ on Bothrops moojeni venom-induced hyperalgesia. Photochem. Photobiol. 2014, 90, 207-213. [CrossRef]

213. Nadur-Andrade, N.; Barbosa, A.M.; Carlos, F.P.; Lima, C.J.; Cogo, J.C.; Zamuner, S.R. Effects of photobiostimulation on edema and hemorrhage induced by Bothrops moojeni venom. Lasers Med. Sci. 2012, 27, 65-70. [CrossRef]

214. Doin-Silva, R.; Baranauskas, V.; Rodrigues-Simioni, L.; Da Cruz-Höfling, M.A. The ability of low level laser therapy to prevent muscle tissue damage induced by snake venom. Photochem. Photobiol. 2009, 85, 63-69. [CrossRef]

215. Barbosa, A.M.; Villaverde, A.B.; Sousa, L.G.; Munin, E.; Fernandez, C.M.; Cogo, J.C.; Zamuner, S.R. Effect of low-level laser therapy in the myonecrosis induced by Bothrops jararacussu snake venom. Photomed. Laser Surg. 2009, 27, 591-597. [CrossRef]

216. Silva, L.M.G.; Da Silva, C.A.A.; Da Silva, A.; Vieira, R.P.; Mesquita-Ferrari, R.A.; Cogo, J.C.; Zamuner, S.R. Photobiomodulation protects and promotes differentiation of C2C12 myoblast cells exposed to snake venom. PLoS ONE 2016, 11. [CrossRef]

217. Nadur-Andrade, N.; Dale, C.S.; da Silva Oliveira, V.R.; Toniolo, E.F.; Dos Santos Feliciano, R.; da Silva, J.A., Jr.; Zamuner, S.R. Analgesic Effect of Photobiomodulation on Bothrops moojeni Venom-Induced Hyperalgesia: A Mechanism Dependent on Neuronal Inhibition, Cytokines and Kinin Receptors Modulation. PLoS Negl. Trop. Dis. 2016, 10. [CrossRef] [PubMed]

218. Flipo, M.; Charton, J.; Hocine, A.; Dassonneville, S.; Deprez, B.; Deprez-Poulain, R. Hydroxamates: Relationships between structure and plasma stability. J. Med. Chem. 2009, 52, 6790-6802. [CrossRef] [PubMed] 